Arqueología del valle de Uspallata (NO de Mendoza): una síntesis actualizada Vanina Victoria Terraza, Erik Marsh, Sol Zárate Bernardi,

Gabriela Da Peña, Daniela Guevara Relaciones, 46(2), e019, julio-diciembre 2021 ISSN 1852-1479 | https://doi.org/10.24215/18521479e019 https://revistas.unlp.edu.ar/relaciones

ISSN 0325-2221 (versión impresa) Sociedad Argentina de Antropología (SAA) Buenos Aires I Argentina

\title{
ARQUEOLOGÍA DEL VALLE DE USPALLATA (NO DE MENDOZA): UNA SÍNTESIS ACTUALIZADA
}

\author{
Vanina Victoria Terraza*, Erik Marsh ${ }^{* *}$, Sol Zárate Bernardi***, \\ Gabriela Da Peña ${ }^{* * * *}$ y Daniela Guevara******
}

Fecha de recepción: 13 de julio de 2021

Fecha de aceptación: 8 de octubre de 2021

\section{RESUMEN}

Transcurridos cincuenta años de la publicación del trabajo "Arqueología del valle de Uspallata, Provincia de Mendoza” escrito por Juan Schobinger en la revista Relaciones, actualizamos la nómina de sitios arqueológicos y sumamos evidencias, datos e interpretaciones generadas desde entonces por diversos equipos de investigación. Se incluyen además aportes específicos de análisis cerámicos, líticos, del arte rupestre, isotópicos, bioarqueológicos, arquitectónicos, entre otros. El tiempo transcurrido desde la publicación original permite discutir cómo ha cambiado la periodización de las ocupaciones del valle y la forma de hacer e interpretar los patrones materiales en una de las principales áreas arqueológicas del Centro-oeste argentino.

Palabras clave: Centro-oeste argentino - periodización - Uspallata - Inca

\footnotetext{
* Instituto de Arqueología y Etnología, Facultad de Filosofía y Letras, Universidad Nacional de Cuyo. E-mail: vaninavterraza@gmail.com

** CONICET, Laboratorio de Paleo-Ecología Humana, Instituto Interdisciplinario de Ciencias Básicas, Facultad de Ciencias Exactas y Naturales, Universidad Nacional de Cuyo. E-mail: emarsh@mendoza-conicet.gob.ar *** CONICET, Laboratorio de Paleo-Ecología Humana, Instituto Interdisciplinario de Ciencias Básicas, Facultad de Ciencias Exactas y Naturales, Universidad Nacional de Cuyo.E-mail: zaratebernardisol@gmail.com **** CONICET, Museo de Ciencias Naturales y Antropológicas Juan Cornelio Moyano. E-mail: gabrieladape87@gmail.com

****** Museo de Ciencias Naturales y Antropológicas Juan Cornelio Moyano. E-mail: guevaramdaniela19@ gmail.com
} 
Relaciones de la Sociedad Argentina de Antropología 46 (2), julio-diciembre 2021: 527-560

ARCHAEOLOGY OF THE USPALLATA VALLEY (NORTHWESTERN MENDOZA): AN UPDATED SYNTHESIS

\section{ABSTRACT}

Fifty years after Juan Schobinger published "Arqueología del valle de Uspallata, Provincia de Mendoza" (Archaeology of the Uspallata Valley, Mendoza province) in the Relaciones research journal, we have updated the list of archaeological sites and added evidence, data, and interpretations produced by several research teams since then. Additionally, specific contributions of ceramic, lithic, rock art, isotopic, bioarchaeological and architectural analyses are included, among others. The time elapsed since the original publication allows us to discuss how the periodization of the valley occupations and the ways of making and interpreting material patterns have changed in one of the primary archaeological areas of midwestern Argentina.

Keywords: Central Western Argentina - periodization - Uspallata - Inca

\section{INTRODUCCIÓN}

Cincuenta años nos separan de la publicación en la revista Relaciones del artículo titulado "Arqueología del valle de Uspallata, Provincia de Mendoza" escrito por Juan Schobinger. Aquella sinopsis preliminar presenta además de un bosquejo geográfico del valle, un listado de sitios arqueológicos conocidos por los investigadores hasta ese momento y plantea para la arqueología de la región una periodización clásica de corte histórico-cultural. Desde mediados del siglo pasado, ha sido el puntapié -junto con los trabajos de Carlos Rusconi- para las investigaciones disciplinares desarrolladas de forma sistemática y profusa en la microrregión. Ellas son el precedente de las que en la actualidad desplegamos como parte de dos equipos independientes, el Grupo de Antropología del Instituto de Ciencias Humanas, Ambientales y Sociales (INCIHUSA-CONICET) y el Laboratorio de Paleoecología Humana del Instituto Interdisciplinario de Ciencias Básicas -LPEH (ICB-CONICET-Universidad Nacional de Cuyo)-. Las temáticas y enfoques desarrollados han variado según los cuestionamientos, las áreas de trabajo y las técnicas analíticas utilizadas, convirtiéndose en un espacio cuantioso de investigaciones, que se caracteriza por presentar ocupaciones desde etapas de cazadores-recolectores hasta época de contacto hispano-indígena y colonial.

Las investigaciones arqueológicas en la región comenzaron con Francisco Aparicio (1940) y Carlos Rusconi (1940, 1956, 1962), pioneros en describir y analizar sitios del valle. El primero de ellos se enfocó en el camino incaico y el tambo de Ranchillos, donde excavó y realizó documentación planimétrica y fotográfica. Rusconi $(1940,1956,1962)$ consignó sitios del fondo de valle (como Potrero El Canal, Campo de la Escuela O'Higgins, Las Bóvedas, Pucará de Uspallata, Potrero Las Colonias, Los Sauces), del piedemonte (Potrero La Chanchería), cordilleranos (Ranchillos y Tambillos) y otros más alejados que no se consignan estrictamente dentro del valle (Potrero Escondido, Canota). Los caracterizó de acuerdo a sus aspectos fisiográficos y a la presencia de rasgos diagnósticos como alfarería en superficie, material lítico, óseo y petroglifos. La descripción se tornó más densa al tratar el Tambo de Ranchillos, al cual adjudicó la categoría de "ciudadela (...) con una población de más de mil almas" (Rusconi 1962:235), e hipotetizó respecto a la funcionalidad del tambo en relación con la población ubicada en el fondo de valle.

Los estudios continuaron con la labor de Juan Schobinger, quien realizó prospecciones desde 1957 y excavaciones a partir de 1970, en el marco del proyecto titulado "Relevamiento arqueológico del Valle de Uspallata" (Schobinger 1971:71). Los resultados se sintetizaron en una nómina de 26 yacimientos, se elaboró una cartografía y se establecieron grandes fases culturales para la microrregión. Schobinger y sus colaboradores continuaron con estudios en el tambo de 
Tambillitos (Schobinger y Bárcena 1971) y en otros sitios de la etapa cerámica (Bárcena 197476b, 1982; Schobinger 1974). Paralelamente a estos estudios, el mismo autor se interesó por la investigación de los santuarios de altura, senderos y tambos anexos en las provincias de La Rioja, San Juan y Mendoza (cerros Negro Overo, El Toro, Mercedario y Aconcagua) (Schobinger 1966, 1967, 1968, 1982, 1985, 1986, 1995a, 1995b), involucrándose además con el análisis del arte rupestre del Centro-oeste argentino -en adelante, COA- (Schobinger 1974-76, 1986, 2001).

Esta tarea en el valle de Uspallata fue continuada por el equipo dirigido por Joaquín Roberto Bárcena, con foco en los sitios incaicos. En un principio los estudios estuvieron orientados al registro y sistematización de los tambos y de la vialidad anexa (Bárcena 1977, 1988, 1993); luego a interpretaciones sobre funcionalidad intra e intersitio y a su jerarquización y vinculación con otras áreas de control estatal dentro y fuera del valle (Bárcena y Román 1990; García Llorca 1991, 1996; Bárcena 1998b, 1999, 2001; Cahiza 1997, 2003; Ots 2002, 2004; Cahiza y Ots 2005), con aportes metodológicos que incluyeron análisis sobre estercoleros, maderas y carbones (Roig y Bárcena 1997, 1998; Bárcena y Dacar 1999-2001), entre otros. Se trabajaron además sitios del precerámico y de la etapa cerámica (Bárcena 1974-76b, 1978, 1982) y se atendió a la conservación y gestión patrimonial (Bárcena 1991, 2004). Más tarde se dirigió la atención hacia sitios del tardío con incidencia incaica en el valle, como Potrero La Chanchería (Terraza 2013, 2020; Bárcena et al. 2015; Terraza y Bárcena 2017). A su vez, como parte de los trabajos de prospección sobre el camino incaico, se concentraron labores en la cuenca del arroyo El Chacay (Bárcena et al. 2017, Terraza et al. 2019).

Asimismo, Víctor Durán y colaboradores desarrollan hace varios años investigaciones en el área del Cerro Tunduqueral, con publicaciones vinculadas al estudio de sus representaciones rupestres (Durán et al. 2010; Zárate Bernardi 2017, Zárate Bernardi et al. 2020) y al análisis del material lítico (Marsh et al. 2021). En el entorno precordillerano se han investigado aspectos como movilidad, subsistencia, dieta, explotación y accesibilidad a fuentes de materias primas (Durán y García 1989; Frigolé y Gasco 2016; Cortegoso et al. 2017), sistemas de producción, organización tecnológica y caracterización lítica (Chiavazza y Cortegoso 2004; Lucero et al. 2006; Castro y Yebra 2018). Se suman estudios isotópicos y bioarqueológicos, estadísticos, arqueométricos y tecnomorfológicos sobre sitios del fondo del valle y del piedemonte uspallatenses (Gil et al. 2014; Novellino et al. 2014; Da Peña et al. 2016; Frigolé 2017; Marsh et al. 2017; Durán et al. 2018). Al mismo tiempo, se han relevado y prospectado sitios en pos de la generación de proyectos de plan de manejo y gestión patrimonial (Durán et al. 2010, 2012a y b; Zárate Bernardi et al. 2019).

\section{CARACTERIZACIÓN DEL VALLE DE USPALLATA}

El valle de Uspallata se localiza en el noroeste de la provincia de Mendoza y pertenece a la subárea arqueológica del COA. Es una depresión tectónica longitudinal con sentido norte-sur, de $100 \mathrm{~km}^{2}$ de extensión en territorio mendocino, cuyas alturas de base van desde los 1.700 a los 2.400 m s.n.m. Se delimita por el valle de Los Patos-Calingasta al norte (provincia de San Juan), Cordón del Plata al sur (aproximadamente 6.000 m), Cordón del Tigre (aproximadamente 5.600 $\mathrm{m}$ ) al oeste y Precordillera (aproximadamente $4.000 \mathrm{~m}$ ) al este. Teniendo en cuenta el nivel de precipitaciones, las temperaturas y la presión atmosférica, el clima del valle de Uspallata puede ser definido como árido, mesotermal, con vegetación de estepa desértica y posibilidad de cultivos bajo riego (Durán et al. 2011). En publicaciones previas, se definió a la microrregión comprendida por los entornos ambientales de cordillera (EC), piedemonte (EP), fondo de valle (EFV) y precordillera (EPr) (Terraza et al. 2019) (figura 1). 


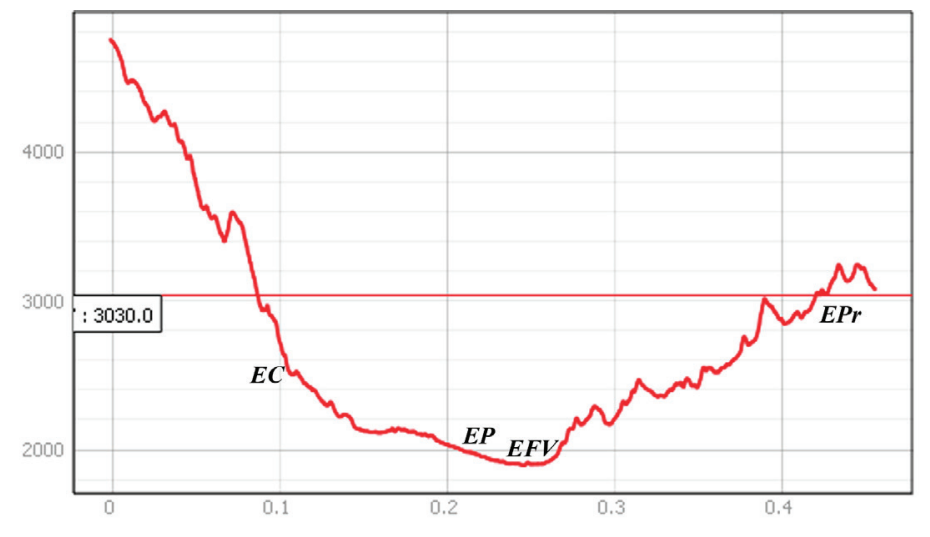

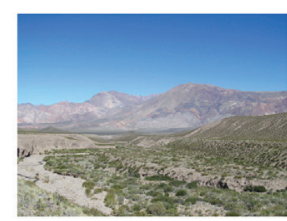

Arroyo El Chacay

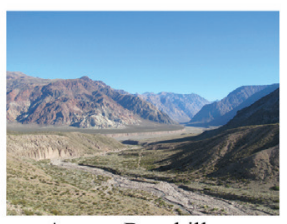

Arroyo Ranchillos

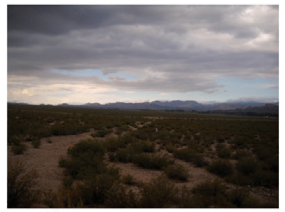

Área La Chanchería

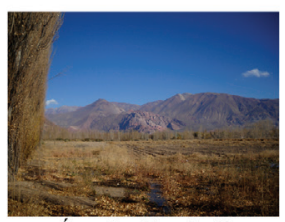

Área La Fundición

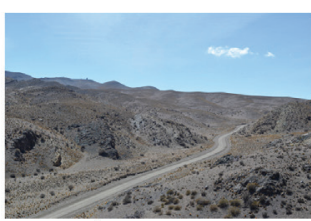

Área Paramillos

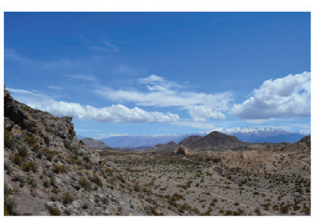

Aguada de Jagüel

Figura 1. Perfil altitudinal y algunos sectores con sitios arqueológicos por entornos ambientales del valle de Uspallata. EC: Entorno cordillerano (El Chacay y Ranchillos); EP: precordillerano (La Chanchería);

EFV: de fondo de valle (La Fundición) y, EPr: precordillerano (Paramillos y Jagüel)

\section{Bosquejo cronológico}

La secuencia ocupacional inicial propuesta para los valles del Diamante, de Uspallata y de Uco-Jaurúa por Lagiglia (1968) se puede dividir en las etapas precerámica y cerámica. La segunda ha sido llamada agroalfarera; en esta ocasión preferimos llamarla "cerámica" ya que "agroalfarera" asume de manera incorrecta la presencia de agricultura y se entiende como una etapa evolutiva. Siguiendo el esquema del NOA, se dividió la etapa cerámica en tres períodos: Temprano, Medio y Tardío (Bárcena 2001; Schobinger 2009a). Estos términos, que provienen del enfoque histórico-cultural propio de la época de los primeros investigadores, se utilizan actualmente en la literatura regional y, en la mayoría de los casos, la simple presencia de cerámica es suficiente para ubicar un contexto a grandes rasgos.

En la discusión de este trabajo se esbozan algunas modificaciones leves a este modelo, sin embargo, el esquema inicial propuesto por los investigadores pioneros de la región sigue siendo útil en cuanto permite ordenar cronológicamente -con ciertas reservas-algunos acontecimientos y procesos de la prehistoria local. Durante varias décadas esta periodización fue la guía para las investigaciones arqueológicas que se llevaron a cabo en el valle. Además, varios de los sitios arqueológicos enunciados en la Sinopsis realizada por Schobinger (1971) solo pueden ser entendidos dentro de este esquema; se trata de sitios que solamente se conocen por estar mencionados en esta publicación, que no fueron retomados por investigaciones posteriores y que, incluso, desapare- 
cieron o son de difícil ubicación por el crecimiento urbano de la villa (Estación Uspallata oeste, Regimiento de Infantería de Montaña 16, Santa Eluisa, entre otros).

La etapa precerámica se extiende cronológicamente desde 12.000 a 1.900 años AP, durante la cual grupos que tenían mayor movilidad desarrollaron prácticas económicas basadas en la caza y la recolección de plantas silvestres. El registro estratificado más temprano de esta parte de los Andes, en el límite Pleistoceno-Holoceno, proviene del sitio Agua de la Cueva, localizado al este del valle, en el entorno precordillerano (García y Sacchero 1989; García 2003; Lucero et al. 2006; Castro y Yebra 2018; entre otros). En el área comprendida entre el valle de Uspallata y el Cordón del Tigre se han localizado varios sitios superficiales caracterizados por la presencia de puntas de proyectil grandes, lanceoladas y triangulares pedunculadas: Estación Uspallata Oeste, Cruz del Paramillo, cercanías de la Ciénaga de Yalguaraz, margen derecha del Arroyo del Tigre, terraza superior del Arroyo del Chiquero, y margen derecha del Arroyo Tambillos (Bárcena 1982), que corresponderían a momentos de transición del Holoceno temprano al medio, alrededor de 8000 años AP (García 2009b).

Para el Holoceno Medio, hasta 4000 años AP, se registran evidencias arqueológicas en los sitios Alero 2 del Arroyo del Tigre (nivel III), Agua de la Tinaja I (nivel IV) y Alero Jagüel III (nivel IV). A nivel regional, se ha interpretado la reducción importante de registros del Holoceno Medio como un descenso demográfico, pero también podría explicarse, en parte, por cambios en los patrones de movilidad y/o un mayor impacto tafonómico (García 2009b; Garvey 2008; Gil et al. 2005; Neme y Gil 2009).

Luego se reduce la movilidad y, en la etapa precerámica final, se registran los primeros cultígenos a nivel regional; en el norte de Mendoza, estos pocos contextos se han fechado alrededor 2500 a 1900 cal BP (Bárcena et al. 1985; Burrieza et al. 2016:110; Gambier 1977; García 1988; Gayo et al. 2019; García y Damiani 2020; Lagiglia 2002). Al parecer, los primeros grupos con plantas domésticas no tenían cerámica y mantenían un grado significativo de movilidad. Este escenario contrasta con intentos argumentativos anteriores de tratar la presencia de cerámica y/o de cultígenos como evidencias de grupos sedentarios y agricultores dentro de una etapa evolutiva definida (ver Gil 1998).

La etapa cerámica de Uspallata se divide en cuatro períodos (aquí seguimos la costumbre académica de usar años d.C. para este lapso): Temprano (50-650 cal d.C.), Medio (650-1000 cal d.C.), Tardío (1250-1400 d.C.) e Incaico (1400 d.C. hasta la llegada española). El Cerámico Temprano se caracteriza por la aparición de grupos con cerámica y, a veces, cultígenos y menos movilidad que la precerámica final. Se encuentran semejanzas con la cultura de Ansilta del sur sanjuanino (Gambier 1977, 2000) y sitios del valle, como nivel III de Agua de la Tinaja I, nivel II de Jagüel III (Bárcena et al. 1985), Jagüel II, nivel I del Alero I del arroyo Tambillos (Bárcena 1982) y Agua de la Cueva Sector Norte (Durán y García 1989).

El Cerámico Medio se define en gran parte por la presencia de un estilo cerámico inciso llamado Agrelo o Calingasta, que se encuentra sobre una región amplia que incluye el norte y centro de Mendoza, el sur de San Juan y unos pocos sitios en zonas de altura de Chile (Gambier 2000; Sanhueza et al. 2004; Prieto Olavarría et al. 2017). Durante este período las sociedades locales comenzaron a ocupar las márgenes del arroyo Uspallata para cultivar, para lo cual invirtieron una importante cuota de trabajo en la derivación de las aguas del arroyo y el mantenimiento de campos de cultivo. Se produciría entonces una disminución de la movilidad, un aumento de la territorialidad y una potenciación del flujo de bienes e información a través de redes de intercambio (Durán et al. 2010). Los grupos del valle se habrían expresado mediante un estilo de arte rupestre grabado, mayormente representado en el Cerro Tunduqueral, que se repite en el Norte Chico Chileno y el oeste de San Juan, lo que sugiere un movimiento de personas e ideas entre estas zonas (Schobinger 2009b y c, Bárcena 2010, 2013; Sabatini y Terraza 2013). No obstante, estudios recientes cuestionan la adjudicación cronocultural monolítica del registro rupestre a este 
periodo (Zárate Bernardi 2017; Zárate Bernardi et al. 2020). En cuanto al registro cerámico, la gran parte de los fechados asociados a la cerámica diagnóstica del Período Medio terminan en el siglo XI, fecha que parece marcar el final de las tendencias materiales del Periodo y coincide con una sequía regional y una disminución fuerte en el registro arqueológico. No obstante, unos pocos fechados tardíos indicarían un lapso más prolongado del uso de la cerámica Agrelo (García 2002).

Respecto a la movilidad humana, un estudio reciente de isótopos de estroncio $\left({ }^{87} \mathrm{Sr} /{ }^{86} \mathrm{Sr}\right)$ identifica una llegada importante de migrantes al valle de Uspallata entre 1270-1420 cal d.C., aunque su origen no se ha determinado (Barberena et al. 2020). Los individuos muestreados provienen de sitios funerarios como Uspallata Usina Sur, Barrio Ramos I, Potrero El Canal, Potrero Las Colonias y Monte de Algarrobos. La subida en densidad de sitios en estos siglos podría indicar un aumento demográfico (Rusconi 1962; Schobinger 1974; Bárcena 1974, 1998a, 2001; Gil et al. 2009; Durán et al. 2018; Barberena et al. 2020). Por su parte, estudios morfométricos craneales permitieron diferenciar biológica y culturalmente un conjunto de individuos con marcadas modificaciones artificiales del cráneo, en los sitios Las Colonias y en Túmulo I y II. Éstos corresponderían a grupos poblacionales que ingresaron a la microrregión después del $1000 \mathrm{AP}$ (Menéndez et al. 2014). Esta presencia de migrantes y una población más densa del valle habría modificado sustancialmente el entorno social y político en las generaciones previas a la llegada del imperio incaico.

Durante varias décadas se cronologizó la llegada de los incas al valle en la segunda mitad del siglo XV, siguiendo las fuentes etnohistóricas (Bárcena 1992; Parisii 1994; Schobinger 2009a) que últimamente se han revelado como poco confiables. Al usar las fechas radiométricas, un modelo bayesiano ubica la presencia inicial inca hacia 1400 cal d.C., que es más coherente con datos de otras partes del imperio (Marsh et al. 2017). Los tres sitios principales incaicos son tambos con estructuras pircadas: Tambillos, Ranchillos y Tambillitos, a lo que se suman sitios como El Chacay con estructuras simples, tramos del camino incaico, sitios de altura con fines ceremoniales como en los Cerros Aconcagua y Penitentes y sitios locales con cerámica incaica como La Chanchería y Ciénaga de Yalguaraz (Bárcena 1998a y b; Schobinger 2001; García 2009a; Terraza et al. 2019). Por su tamaño y organización espacial, se interpreta a Ranchillos como el foco de actividad inca. Se piensa que los contactos iniciales y posteriores podrían haber pasado entre este lugar y el valle de Aconcagua, una posibilidad que es coherente con las tendencias en los fechados del Chile Central (Puerto Mundt y Marsh 2021). Esta posibilidad también se apoya en la impronta material menor y posterior del imperio inca al norte, este y sur del valle (Cahiza y Ots 2005; García 2011; Michieli 2011; Ots et al. 2011; Ots y Cahiza 2013; Zárate Bernardi et al. 2020) (tabla 1).

\section{LOS SITIOS ARQUEOLÓGICOS}

Partimos de una concepción amplia y abarcativa que define al sitio arqueológico no solo a partir de la presencia de estructuras, concentraciones de materiales y/o hallazgos aislados en superficie, sino que además incorpora a áreas arqueológicas extensas y al sistema vial incaico, entendiendo que todas estas posibilidades forman parte de la construcción de paisajes culturales. Los sitios arqueológicos presentados por Schobinger en su relación preliminar contabilizaban un total de veintiséis. En esta ocasión, se apartaron los últimos tres sitios (Petroglifos del río Colorado, Punta de Vacas y Las Cuevas) porque están ubicados por fuera de la microrregión. Por razones de extensión del escrito, se dejó de lado la Zona Norte del valle, ubicada en las cercanías de la Ciénaga de Yalguaraz, y la Zona Este correspondiente a los hallazgos de precordillera. Al mismo tiempo, se incorporaron al listado dos locaciones arqueológicas, El Chacay y Barrio Ramos I, dado que se ubican geográficamente en la cordillera y en el fondo del valle, entornos preferenciales en 
Vanina V. TerRaza y otros - Arqueología del Valle de UspalLata (NO de MENDoza): una síntesis ...

Tabla 1. Asignaciones temporales de los sitios del valle de Uspallata

\begin{tabular}{|c|c|c|c|}
\hline $\mathbf{N}^{\circ}$ & Sitio & Asignación temporal & Referencia bibliográfica \\
\hline 1 & Estación Uspallata Oeste & Precerámico & Schobinger 1971 \\
\hline 2 & Puente & $\begin{array}{l}\text { Cerámico Temprano- } \\
\text { Medio }\end{array}$ & Durán et al. 2012; Schobinger 1971 \\
\hline 3 & Usina Sur & $\begin{array}{l}\text { Cerámico Temprano- } \\
\text { Medio }\end{array}$ & $\begin{array}{l}\text { Barberena et al. 2020:3; Durán et al. 2012; } \\
\text { Schobinger 1971, 1974-76 }\end{array}$ \\
\hline 4 & Uspallata Sudeste & $\begin{array}{l}\text { Cerámico Temprano- } \\
\text { Medio }\end{array}$ & Durán et al. 2012; Schobinger 1971 \\
\hline 5 & $\begin{array}{l}\text { Potrero El Canal } \\
\text { (Túmulos I a III) }\end{array}$ & $\begin{array}{l}\text { Cerámico Temprano- } \\
\text { Tardío }\end{array}$ & $\begin{array}{l}\text { Durán et al. 2012; Gil et al. 2014; } \\
\text { Menéndez et al. 2014; Rusconi 1962; } \\
\text { Schobinger } 1971\end{array}$ \\
\hline 6 & $\begin{array}{l}\text { Potrero Las Colonias } \\
\text { (osario y Las Lomas) }\end{array}$ & Cerámico Tardío & $\begin{array}{l}\text { Durán et al. 2012; Gil et al. 2014: 219; } \\
\text { Menéndez et al. } 2014\end{array}$ \\
\hline 7 & Monte de Algarrobos & Inca & Barberena et al. 2020:3; Durán et al. 2012 \\
\hline 8 & $\begin{array}{l}\text { Restos humanos en } \\
\text { estado subfósil }\end{array}$ & Precerámico & Rusconi 1962 \\
\hline 9 & Cerrillos al SO de la villa & Sin referencia temporal & Schobinger 1971 \\
\hline 10 & \begin{tabular}{|l|} 
Regimiento de Infantería \\
de Montaña 16 \\
\end{tabular} & Sin referencia temporal & Schobinger 1971 \\
\hline 11 & Escuela O’Higgins & Sin referencia temporal & Schobinger 1971 \\
\hline 12 & Santa Eluisa & Sin referencia temporal & Schobinger 1971 \\
\hline 13 & Potrero La Chanchería & $\begin{array}{l}\text { Cerámico Medio-Tardío } \\
\text { e Inca }\end{array}$ & $\begin{array}{l}\text { Bárcena 2011, 2015; Frigolé 2017; } \\
\text { Schobinger 1971 }\end{array}$ \\
\hline 14 & Santa Elena & $\begin{array}{l}\text { Cerámico Temprano- } \\
\text { Medio }\end{array}$ & Durán et al. 2012; Schobinger 1971 \\
\hline 15 & Las Bóvedas & $\begin{array}{l}\text { Cerámico Temprano- } \\
\text { Medio }\end{array}$ & Schobinger 1971 \\
\hline 16 & Los Sauces & $\begin{array}{l}\text { Cerámico Temprano- } \\
\text { Medio }\end{array}$ & Durán et al. 2012; Schobinger 1971 \\
\hline 17 & $\begin{array}{l}\text { Uspallata Norte y } \\
\text { Tunduqueral Norte }\end{array}$ & $\begin{array}{l}\text { Cerámico Temprano- } \\
\text { Medio }\end{array}$ & $\begin{array}{l}\text { Durán et al. 2012; Marsh et al. 2021; } \\
\text { Schobinger 1971 }\end{array}$ \\
\hline 18 & \begin{tabular}{|l|} 
Cerro y Alero \\
Tunduqueral
\end{tabular} & $\begin{array}{l}\text { Cerámico Temprano- } \\
\text { Medio }\end{array}$ & Durán et al. 2012; Schobinger 1971 \\
\hline 19 & Petroglifo del Peñón & $\begin{array}{l}\text { Cerámico Temprano- } \\
\text { Medio }\end{array}$ & Durán et al. 2012; Schobinger 1971 \\
\hline 20 & Tambillos & Inca & $\begin{array}{l}\text { Bárcena 1988, 1993, 1998a: 153, 245-246; } \\
\text { Bárcena y Román 1990; Rusconi 1962; } \\
\text { Schobinger 1971; }\end{array}$ \\
\hline 21 & Ranchillos & Inca & $\begin{array}{l}\text { Bárcena 1998a: 155-156, 247-248, b; } \\
\text { Rusconi 1962; Schobinger 1971 }\end{array}$ \\
\hline 22 & Tambillitos & Inca & Bárcena 1998a: 156; Schobinger 1971 \\
\hline 23 & El Chacay & Inca & Terraza et al. 2019 \\
\hline 24 & Barrio Ramos & Cerámico Tardío e Inca & $\begin{array}{l}\text { Bárcena 1998a: 152, 227; Durán et al. 2012, } \\
\text { 2018; Gil et al. 2014: 219; Menéndez et } \\
\text { al. 2014 }\end{array}$ \\
\hline
\end{tabular}


Relaciones de la Sociedad Argentina de Antropología 46 (2), julio-diciembre 2021: 527-560

(Tabla 1. Continuación)

\begin{tabular}{|c|c|c|c|}
\hline $\mathbf{N}^{\circ}$ & Sitio & Asignación temporal & Referencia bibliográfica \\
\hline \multirow{6}{*}{ 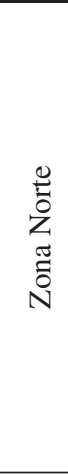 } & Ciénaga de Yalguaraz & $\begin{array}{l}\text { Precerámico, Cerámico } \\
\text { e Inca }\end{array}$ & Bárcena 1977, 1981, 1982 \\
\hline & $\begin{array}{l}\text { Margen derecha del } \\
\text { Arroyo del Tigre }\end{array}$ & Precerámico & Bárcena 1981, 1982 \\
\hline & \begin{tabular}{|l|} 
Alero II del Arroyo del \\
Tigre
\end{tabular} & $\begin{array}{l}\text { Precerámico, Cerámico } \\
\text { Medio }\end{array}$ & Bárcena 1981, 1982 \\
\hline & \begin{tabular}{|l|} 
Terraza superior del \\
Arroyo del Chiquero \\
\end{tabular} & Precerámico & Bárcena 1981, 1982 \\
\hline & \begin{tabular}{|l} 
Alero I del Arroyo \\
Tambillos \\
\end{tabular} & Cerámico Temprano & Bárcena 1982 \\
\hline & $\begin{array}{l}\text { Margen derecha del } \\
\text { Arroyo Tambillos }\end{array}$ & Precerámico & Bárcena 1981, 1982 \\
\hline \multirow{5}{*}{ 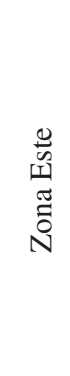 } & Agua de la Tinaja I & \begin{tabular}{|l|} 
Precerámico, Cerámico \\
Temprano
\end{tabular} & Bárcena et al. 1985 \\
\hline & Alero Jagüel III & \begin{tabular}{|l} 
Precerámico, Cerámico \\
Temprano
\end{tabular} & Bárcena 1982; Bárcena et al. 1985 \\
\hline & Jagüel II & Cerámico Temprano & Bárcena 1982 \\
\hline & Agua de la Cueva & $\begin{array}{l}\text { Precerámico, Cerámico } \\
\text { e Inca }\end{array}$ & $\begin{array}{l}\text { García y Sacchero 1989; García } 2003 \text { a } \\
\text { y b; Lucero et al. 2006; Castro y Yebra, } \\
\text { 2018; Durán y García } 1989\end{array}$ \\
\hline & Cruz del Paramillo & Precerámico & Schobinger 1971 \\
\hline
\end{tabular}

la versión original (figura 2). Para la descripción tuvimos en cuenta aspectos como localización, materialidades asociadas, relaciones espaciales intersitios, posibles funcionalidades, entre otros. En algunos sitios se mantuvo la caracterización del sitio publicada en 1971, debido a que no se han generado nuevos datos. Presentamos los fechados con su mediana calibrada y redondeada por 10 años según la curva de calibración SHCal20 (Hogg et al. 2020), sin descartar los rangos de error en su interpretación.

\section{Estación Uspallata Oeste}

A un kilómetro al oeste de la antigua estación Uspallata del ferrocarril trasandino, se hallaron materiales líticos de forma aislada. Schobinger (1971) mencionó artefactos basálticos y puntas de proyectil, una de las cuales tendría pedúnculo triangular y $75 \mathrm{~mm}$ de largo. Se la asignó a la etapa precerámica.

\section{Puente}

En las cercanías al puente que cruza el río Mendoza antes de llegar a Uspallata, Schobinger (1971:72) localizó un sitio con estructuras pircadas, con fragmentos de cerámica gris incisa, moletas y una punta de proyectil triangular grande. El autor postuló que sería un mirador y lo asoció a los ocupantes del yacimiento Uspallata Norte. 

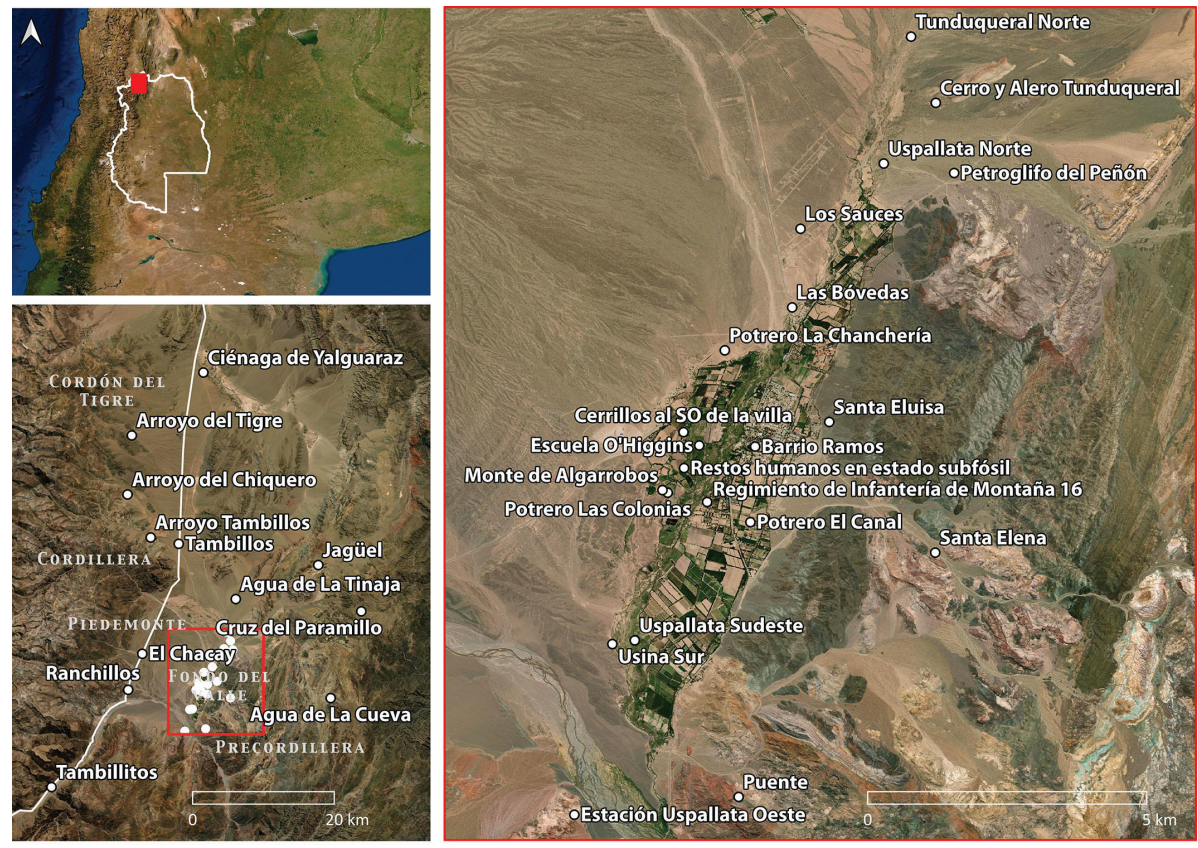

Figura 2. Localización de los sitios arqueológicos mencionados en el trabajo y del Qapaq ñan, valle de Uspallata (NO de Mendoza)

\section{Usina Sur}

Sitio ubicado a $1,5 \mathrm{~km}$ al sur de la usina hidroeléctrica y a $7 \mathrm{~km}$ de la villa, en una planicie angosta sobre el borde de una barranca, debajo de la cual se localiza la ribera oeste del arroyo Uspallata. Es descrita como una 'zona' integrada por cinco concentraciones espaciales: un enterratorio múltiple, tres soportes con arte rupestre y un barreal en donde se halló una fuente de roca basáltica y forma ovalada (Schobinger 1971); se interpreta como un lugar de diversas actividades económicas y simbólicas, si bien con una intensidad baja (Da Peña et al. 2018). Los relevamientos realizados desde 2017 dan cuenta de elementos dispersos en superficie como lascas, tiestos y fragmentos de instrumentos de molienda.

Entre el material óseo recuperado se encontraron restos desarticulados en superficie, producto de los procesos erosivos que afectaron la zona (Schobinger 1971; 1974-76). Se realizaron dos sondeos, de los cuales se extrajeron cinco cráneos y restos poscraneales acompañados de ajuar a $2 \mathrm{~m}$ de profundidad (S-1) y restos de dos individuos sin material arqueológico asociado (S-2) (figura 4). Bárcena (1974-76a) realizó el análisis antropométrico y craneotrigonométrico de los elementos óseos craneales y postcraneales, sumado a la comparación de los resultados obtenidos con la información disponible para otros sitios del valle, publicada por Rusconi en 1962 (Túmulos I y II y Potrero Las Colonias). Esto permitió plantear las primeras aproximaciones sobre la identificación racial de los individuos recuperados del sitio. Se cuenta con un fechado radiocarbónico (Bárcena 1998a) con una mediana de 1400 cal d.C., que lo coloca justo antes o después de la llegada incaica, de acuerdo con la cronología propuesta para la zona por Marsh et al. (2017).

El ajuar está compuesto por una fuente de ofrendas de roca, un vaso de roca pulida, una pipa con hornillo en la parte central y con terminación ofídica/fálica en el extremo opuesto, un tembetá alargado, cilíndrico, un adorno colgante fusiforme, una cuenta de collar de piedra, die- 
ciséis puntas de proyectil de obsidiana, dos de sílex y dos de cuarzo; impresiones de cestería en arcilla; también se registran piezas confeccionadas en bronce: una placa trapezoidal, un cuchillo arqueado, una pinza para depilar, una placa con forma de hacha y una cuña con acanaladura (Schobinger 1974-76). Los análisis químicos y metalográficos condujeron a concluir la procedencia foránea de las piezas metalúrgicas, específicamente vinculada al Altiplano andino (Bárcena 1974-76b). Asimismo, estudios químicos y morfológicos-experimentales sobre las puntas de proyectil de obsidiana establecieron la localización de la fuente de esta roca a 300 km al sur del hallazgo, en Arroyo de Las Cargas, así como la presencia de una considerable uniformidad morfológica, técnica y dimensional de la muestra. Se propuso que fueron hechas por cazadores-recolectores del sur de Mendoza y que ingresaron por intercambio al valle de Uspallata (Nami et al. 2015).

En el año 2017 se prospectó la zona excavada previamente y las barrancas aledañas (Da Peña et al. 2018; figura 4) y se registró la presencia de restos óseos craneales y poscraneales, desarticulados y fragmentados como consecuencia de la erosión de la barranca donde se dejaron los difuntos. De acuerdo con el cálculo de NMI se pudo determinar la correspondencia del material osteológico recuperado a cuatro individuos (dos subadultos y dos adultos). En una primera interpretación sobre su vinculación con las excavaciones realizadas por Schobinger en 1970-71, se propuso la posibilidad de que formasen parte de la excavación S-2 (Da Peña et al. 2018). En un trabajo reciente se dio a conocer un fechado con una mediana de 1280 cal d.C. (772 \pm 25 AP, D-AMS-033193) (Barberena et al. 2020:3), que lo coloca en un contexto anterior a la llegada incaica a la región. Según su huella de isótopos estables de estroncio $\left({ }^{87} \mathrm{Sr} /{ }^{86} \mathrm{Sr}\right)$, forma parte del patrón de los migrantes en esta época (Barberena et al. 2020:5).

En los soportes de arte rupestre se destacan motivos curvilíneos comparables con los de Cerro Tunduqueral. El primero se sitúa a unos $100 \mathrm{~m}$ de la zona del enterratorio, mientras que otro menor y menos intensamente grabado se ubica a $300 \mathrm{~m}$ hacia el suroeste del anterior. El soporte mayor (de $2 \mathrm{~m}$ de alto por 3,5 de ancho) está próximo a concentraciones de material arqueológico en superficie y al sector de barrancas donde se encuentran los entierros, y cuenta con siete paneles y un total de veintinueve figuras grabadas. La mayoría de las figuras corresponden a líneas rectas y sinuosas finas y poco profundas. Destacan en el panel principal (el mayor en tamaño, orientado hacia el este) tres figuras: un 'mascariforme' o antropomorfo aureolado, con características similares a otros relevados en el valle y zonas del suroeste de San Juan y valles centrales chilenos (Sabatini y Terraza 2013; Zárate Bernardi 2017), un camélido y una figura ancoriforme, la única realizada mediante piqueteado areal (figura 3). Figuras semejantes al ancoriforme han sido asignadas al arte rupestre del Período Tardío en el Centro Norte de Chile y en el COA (García 2014; Zárate Bernardi et al. 2020); se los asocia a tumis, y se los vincula a símbolos de poder incorporados en épocas del dominio incaico, tanto en el norte de Chile (Montt y Pimentel 2003) como en el Noroeste argentino (NOA) (Hernández Llosas 2006; Martel y Giraudo 2014). A su vez, esta figura presenta similitudes formales con la placa de bronce del ajuar de uno de los entierros múltiples situado en las proximidades del soporte; al respecto, los objetos de este metal se corresponderían con el periodo de dominación inca en la región (Zárate Bernardi et al. 2020).

\section{Uspallata Sudeste}

Mencionado por Schobinger (1971) como concentraciones de material cerámico y lítico sobre superficies acotadas en extensión en la zona de La Fundición, en particular de cerámica gris e instrumentos de molienda. En la actualidad el área se encuentra totalmente modificada por la actividad agrícola y forestal. 


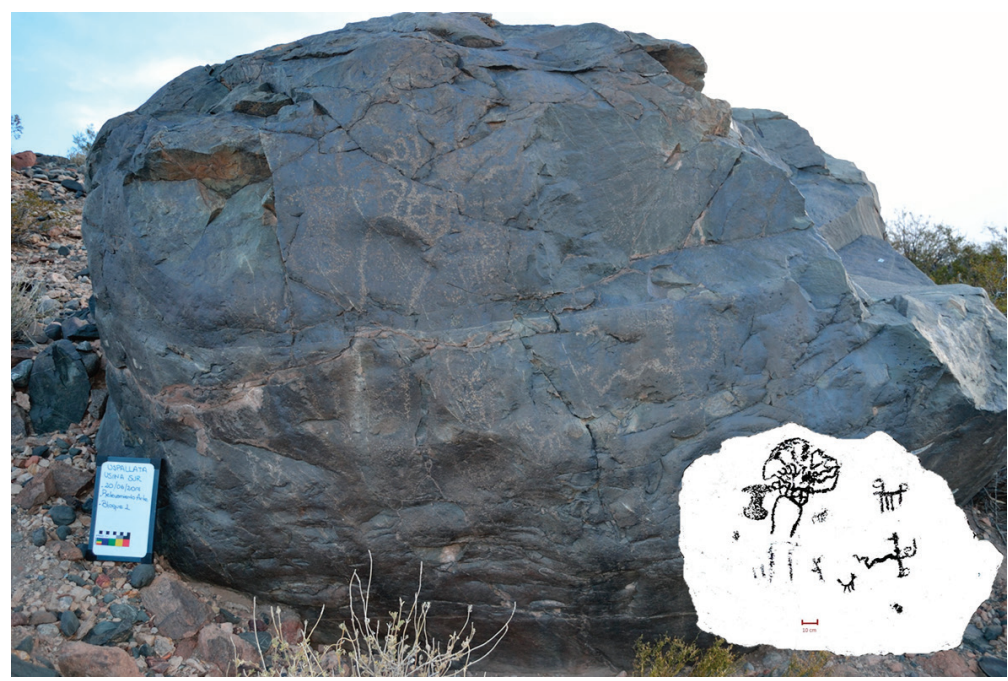

Figura 3. Petroglifo del sitio Usina Sur. Autoría: Sol Zárate Bernardi

\section{Potrero El Canal: Túmulos I, II y III}

Conjunto de estructuras funerarias de tipo montículos localizadas a unos tres kilómetros al sur del Gran Hotel Uspallata "y a la izquierda de la calle que conducía al puente del río Mendoza" según trabajos llevados a cabo en 1938 (Rusconi 1962:186). Se contabilizaron cinco estructuras, de las cuales tres fueron excavadas (Túmulos I, II y III) y solo el Túmulo II fue descrito en detalle (Rusconi 1962; figura 4).

A partir de un análisis bioarqueológico realizado por Da Peña y colaboradores (2016) se planteó la existencia de tres patrones de entierro diferenciados, flexionado, extendido y un caso de restos desarticulados (que fue interpretado como un entierro secundario), lo que llevó a considerar al sitio como un área formal de entierro utilizado de manera recurrente. Por otro lado, se registró la presencia de lesiones óseas vinculadas con traumas en el individuo 245 (trauma por compresión en el cráneo y doble fractura de cúbito y radio izquierdos, es decir, una fractura de parry). Los individuos adultos de la muestra presentan lesiones osteoarticulares tanto en el esqueleto axial como apendicular. En relación con los análisis dietarios, se vincularon los datos obtenidos de salud bucal y estrés sistémico con la información isotópica disponible, que sugiere una dieta con un consumo de plantas $\mathrm{C}_{4}$, posiblemente maíz (Gil et al. 2014).

Al individuo masculino 245 lo acompañaban dos ollas de características estilísticas similares a los complejos Bato y Llolleo, que tuvieron su desarrollo durante el Periodo Alfarero Temprano (PAT) en la zona central de Chile (Planella y Falabella 1987). De esta forma, constituirían un indicador para afirmar la presencia de redes de intercambio entre poblaciones trasandinas (Lagiglia 1997; Falabella et al. 2001; Cortegoso 2004; Sanhueza et al. 2004; Durán et al. 2006; Frigolé et al. 2014).

Por otro lado, y de acuerdo con las descripciones de la excavación, un tembetá asignado al tipo IV por Rusconi (tembetá con botón chato de figura circular y superficie cóncava, provisto de dos aletas laterales basales), fue hallado sobre el mentón del individuo femenino 239, quien también presenta un tipo de desgaste en forma de surco en la arcada anterior de las piezas dentales del maxilar, por lo que ha sido interpretado como forma de diferenciación intragrupal o el uso del aparato masticatorio como "tercera mano" (Da Peña et al. 2016; Molleson 2007). Por último, se halló en el interior del tórax del individuo masculino 241 una punta de proyectil triangular, de base escotada, fabricada en material silíceo. 
En cuanto a los túmulos I y III, las descripciones realizadas por Rusconi (1962) son breves y escasas. En ambos casos, se trata de inhumaciones con presencia de restos óseos desarticulados y mezclados. El Túmulo I habría sido perturbado previamente por la acción de "huaqueros" y se componía de restos de aproximadamente 20 individuos, según cálculos del autor. No obstante, en el 2019 se actualizó el número mínimo de individuos (NMI) del sitio, contabilizando 29 individuos. Por otro lado, el Túmulo III se caracteriza por la presencia de restos de jóvenes y párvulos principalmente, con un NMI de 27 individuos.

En relación con la información cronológica de los sitios, el Túmulo II cuenta con dos fechados de AMS sobre hueso: $1178 \pm 41$ y $1269 \pm 35$ AP, lo que lo ubica en el periodo cerámico medio; en tanto el Túmulo I: $977 \pm 35$ y el Túmulo III: $671 \pm 40$ AP, se posicionarían en un bloque temporal más tardío, cercano a los tomados para Barrio Ramos y Potrero Las Colonias (Gil et al. 2014:220; Menéndez et al. 2014:105).

Las muestras de estroncio tomadas para 21 individuos de Túmulo I (4), Túmulo II (14) y Túmulo III (3) indican que 20 de ellos presentan señales isotópicas locales, en tanto que uno de los individuos del Túmulo III presenta un rango isotópico no local, que permite interpretarlo como migrante, semejante en señal a las muestras del Potrero Las Colonias (Barberena et al. 2021:4).

\section{Potrero Las Colonias}

Esta zona, descripta por Rusconi (1962), estaba compuesta por dos áreas: un osario y 'Las Lomas', sector en el que se encontraban pequeños soportes con petroglifos. En la actualidad, si bien la zona ha sido prospectada, los soportes y el lugar del hallazgo del osario no han sido localizados. Esto se debe a que el área presenta una alteración profunda vinculada a la actividad agrícola y residencial desarrolladas.

El Potrero limitaba al oeste con el camino internacional a Chile, al este con el río Uspallata y al sur con una cerrillada de ripios. El osario, ubicado a $50 \mathrm{~m}$ al pie de uno de estos cerrillos, presentó un NMI de 119, acompañados de carbón vegetal y restos de alfarería quemadas. Rusconi (1965) describió el entierro como una fosa colectiva, de huesos mezclados y de restos esqueléticos articulados que habían sido depositados sin orden aparente, algunos en posición de cuclillas con la cabeza orientada hacia el norte y otros restos dirigidos hacia el sur (figura 4).

Recientemente, se muestrearon siete individuos al azar para el análisis isotópico. Estos tienen valores no locales de estroncio y se interpretan como migrantes y se ubican en la fase 1280-1420 cal d.C. (Barberena et al. 2020:5). El análisis paleodietario registró un consumo muy elevado de recursos $\mathrm{C}_{4}$, que sugiere una subsistencia basada en la agricultura del maíz para este lapso. Los autores hipotetizan que estos individuos procederían de un sistema social intensivo, caracterizado por una baja flexibilidad social y geográfica, una elevada relación genética entre grupos co-residentes, y una economía "focal" o intensificada (Barberena et al. 2021:26).

\section{Monte de Algarrobos}

Dentro y al oeste del antiguo Potrero Las Colonias, en las cercanías de montículos de tierra cubiertos por algarrobos, se identificaron dos sitios con entierros (Rusconi 1962: figura 158). El primero de ellos se trata de un individuo en posición decúbito lateral y en flexión, acompañado por los restos óseos de un perro. En 1940, al momento de extraerse los esqueletos, se observaron piedras alrededor, inclusive una conana (Rusconi 1962:219).

El segundo sitio, ubicado a pocos metros del anterior, es un enterratorio simple de un individuo femenino con una huella de estroncio no local (Barberena et al. 2020), acompañado por 
un ajuar funerario notable: una jarra completa con pintura roja, otra jarra conservada solo en su mitad inferior con restos de hollín y un puco engobado y pintado, en el interior del cual se hallaron torteros de hueso elipsoidales (Rusconi 1962: 220).

Schobinger identificó los montículos y recogió numerosa cerámica -“inclusive del tipo Inca" (Schobinger 1971:75)-, puntas de proyectil y manos de moler. El fechado obtenido tiene una mediana de 1640 cal d.C. (298 \pm 28 , D-AMS-030192) pero con un rango de probabilidad que se extiende hasta la época incaica (Barberena et al. 2020:3). Eso deja abierta la interpretación de un contexto pre o posthispánico, en cual caso mostraría la supervivencia de prácticas y materiales prehispánicos o con un ajuar heredado.

Las características tecnológicas y morfométricas de la jarra, como otras ollas/jarras encontradas en contextos de entierros en el valle (como la olla/jarra del sitio Barrio Ramos I), indican que podría tener influencias trasandinas (Bárcena 1998a:223, 2001:59-62; Durán et al. 2018:72-73). La morfología y decoración del puco se asignan a la tradición diaguita chilena, con un diseño no figurativo en técnica de pintura negra sobre engobe crema: las volutas y grecas en reflexión (Terraza y Auteri 2020). Estos patrones de diseño se hallan en piezas que pertenecen al universo representativo diaguita chileno, pero cuyo origen es inca cuzqueño (González Carvajal 2013). Se trataría entonces de una pieza manufacturada por alfareros trasandinos que han incorporado iconografía propiamente cuzqueña en tiempos de la dominación estatal.
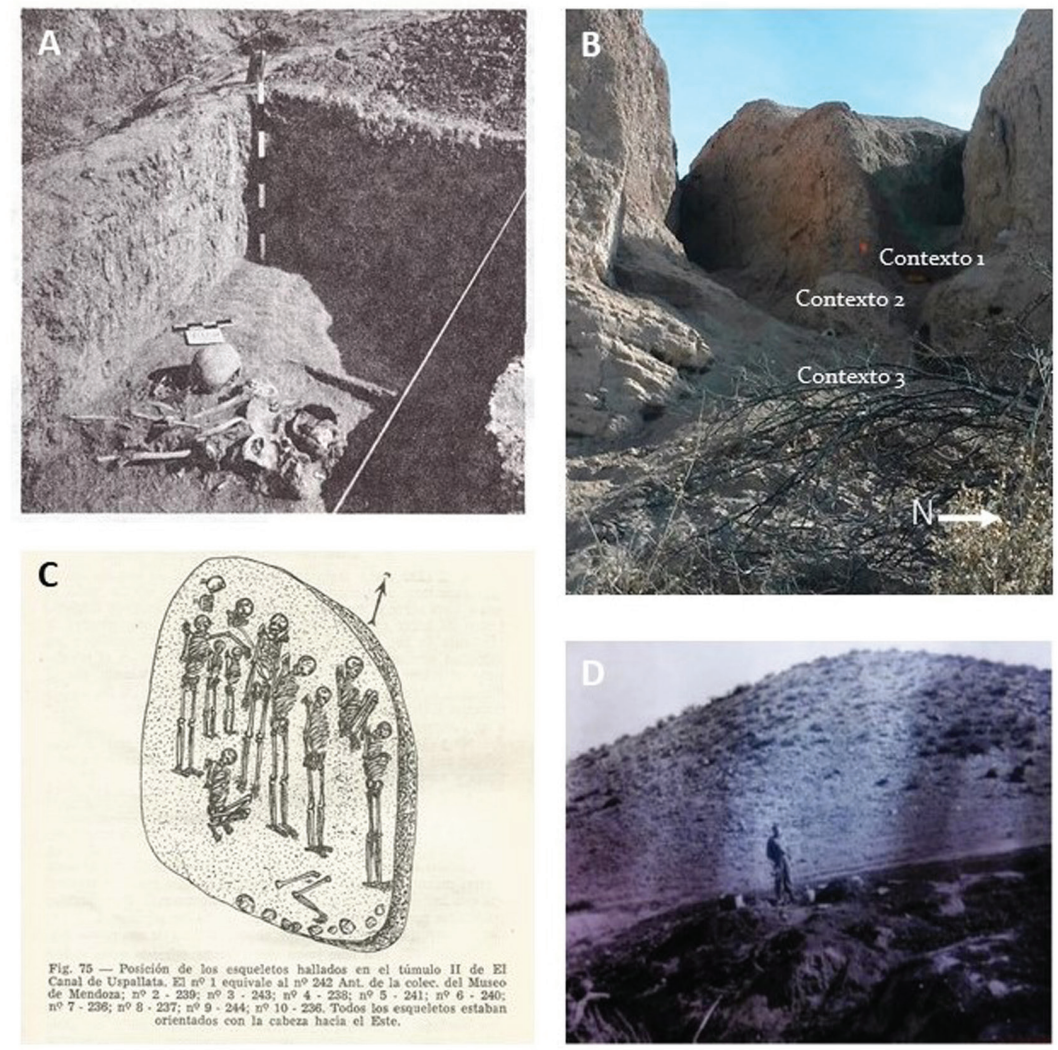

Figura 4. Sitios con inhumaciones del valle de Uspallata. A: Excavación S-2 del sitio Uspallata Usina Sur (extraído de Schobinger 1974-76). B: Ubicación de contextos de rescate a $12 \mathrm{~m}$ del sitio Uspallata Usina

Sur (Da Peña et al. 2018). C: Dibujo con ubicación de los individuos del sitio Túmulo II (extraído de Rusconi 1962). D: Fotografía del hallazgo de restos óseos humanos en superficie correspondientes al sitio Potrero Las Colonias (gentileza de Estela Rusconi, hija de Carlos Rusconi) 
El hecho de que a este individuo lo asistieron piezas cerámicas vinculadas a grupos del Norte Chico chileno o de Chile central podría denotar relaciones intergrupales transcordilleranas, así como prácticas asociadas al traslado, intercambio, uso y (re) significación de cerámica en el valle de Uspallata (Terraza y Auteri 2020).

\section{Restos humanos en estado subfósil}

Al norte del Potrero Las Colonias y en el barranco de un cauce seco, Rusconi (1962: figura 158) halló un cráneo subdolicocéfalo sin deformación y otros restos óseos humanos, atribuidos por el autor a momentos del Holoceno Temprano o Medio.

\section{Cerrillos al SO de la villa}

A una distancia de 1,5 km de la villa, en lo que actualmente es una propiedad privada, Rusconi (1962) registró una estructura semicircular de muros pircados derruidos de $15 \mathrm{~m}$ de diámetro, a la que denominó "pucará", y describió once soportes pequeños con petroglifos ubicados en la ladera oeste de uno de los cerrillos. El mismo investigador da cuenta de que tres de esos bloques fueron trasladados al museo Cornelio Moyano para su conservación. Más tarde, Schobinger (1971) visitó el sitio, cuestionó la denominación y funcionalidad de pucará y le otorgó una función ritual. Además, halló fragmentos cerámicos al pie septentrional de este cerro y una concentración de lascas y restos cerámicos grises incisos en las estribaciones de otra de las elevaciones.

Actualmente, cuatro de los bloques descriptos por Rusconi han desaparecido del sitio, pero se han relevado dos más que no se encuentran en la bibliografía arqueológica, por lo que hay cinco soportes in situ. Se trata de bloques redondeados, con pátina oscura y grabados poco profundos, en su mayoría motivos no figurativos. Se destaca un antropomorfo con penacho. En 2015 se realizó un sondeo exploratorio dentro de la estructura pircada y no se halló material en estratigrafía, tampoco en superficie.

\section{Regimiento de Infantería de Montaña 16}

Schobinger (1971) nombra el hallazgo de puntas de proyectil, entre las que destaca una triangular de tamaño pequeño sobre cuarzo blanco, fragmentos de cerámica y una moleta, en el campo de ejercicios de este establecimiento militar.

\section{Escuela O'Higgins}

En los terrenos de esta institución educativa, a 800 m al sur de la villa, Rusconi (1962) observó fragmentos de cerámica gris sin decoración.

\section{Santa Eluisa}

A un kilómetro al SE de la villa, Rusconi (1962) recogió fragmentos de alfarería alisada y partes de un puco pintado, además de piezas líticas. 


\section{Potrero La Chanchería}

Ubicado en el piedemonte alto al oeste de la localidad de Uspallata, es un sitio superficial descrito por primera vez en 1938 (Rusconi 1962), caracterizado por presentar abundante material cerámico (alfarería lisa, pintada y engobada) y lítico (puntas de flecha, molinos, manos de moler y piedras de boleadoras).

Fue Schobinger (1971) quien recalcó la abundancia de cerámica a nivel superficial, diferenciándola de los demás sitios cercanos por no ser de tipo local o temprano, sino por tener similitudes a las halladas en los tambos incaicos situados al oeste del sitio. El autor destacó que era el único sitio inca sin construcciones pircadas conocido en el occidente cuyano y que posiblemente se tratase de una avanzada incaica destinada a puesto de comercio entre sus súbditos y los pobladores uspallatenses (Schobinger 1971:76-77).

A fines de la década de 1970 vuelve a ser mencionado como un sitio con evidencias de ocupación incaica (Bárcena 1977:663) y más tarde, el mismo autor plantea su conexión con el tambo de Ranchillos - por una senda que atravesaría la Pampa de Tabolango y el curso inferior del Arroyo del Chacay- y su función como enclave subsidiario de relación con los habitantes del valle (Bárcena 1998b:5).

Bárcena ha realizado prospecciones y sondeos en un sector del yacimiento, al que denominó Chanchería I, donde reconoció material lítico y cerámica. Estos trabajos destacaron la presencia de cerámica de las poblaciones locales tardías del valle, las cuales se diferenciarían de los tipos inca provincial, diaguita chileno en su fase de aculturación incaica o bien de los tipos locales bajo dominación del Tawantinsuyu, por ser grises y con decoración incisa o grabada. Asimismo, contrastó la superposición de los distintos estilos con la secuencia establecida sobre la base de dataciones por termoluminiscencia, que ofrecieron la cronología de $505 \pm 50$ años AP para la cerámica de estilos incaicos y $580 \pm 60$ años AP para la cerámica gris incisa. El autor postuló la ocupación del área por parte de poblaciones locales durante el periodo tardío y su persistencia en el lugar bajo dominación incaica (Bárcena 2011).

En continuidad con estos estudios, se determinaron algunas características morfo-tecnológicas y estilísticas de los tipos cerámicos presentes en la locación, apuntando ciertas relaciones con los tipos cerámicos propios de los sitios incaicos, en especial con la propia del tambo de Ranchillos (Terraza 2013). Los análisis continuaron con publicaciones editadas (Bárcena et al. 2015; Terraza y Bárcena 2017). En 2015 se realizó una campaña colaborativa entre equipos de prospecciones y excavación. Con un croquis de sondeos de prueba, se confirmó la ausencia de estructuras en el área y la tendencia fuerte de superficialidad de la mayor parte del registro arqueológico. Se obtuvo un fechado de superficie asociado a un fogón, huesos de camélido y cerámica tipo Agrelo que arrojó una fecha con una mediana de 790 cal d.C. (1300 \pm 80 años AP, LP-2992) (Frigolé 2017:34). Este contexto da cuenta de un uso anterior del espacio. Su posición superficial indica que ocupaciones posteriores habrían disturbado evidencias anteriores.

Recientemente se puso el foco en las tradiciones cerámicas presentes y se señalaron posibles orígenes sociales específicos de sus hacedores/portadores. Además, se denominó el sitio como "mixto", un nodo central en la conformación de la red poli-espacial del valle. Se piensa que su ubicación intermedia entre entornos físicos y culturales disímiles colaboró en su potencialidad como lugar de encuentro entre las sociedades locales y los grupos inca/incaizados. El registro material hablaría entonces de un taskscape donde probablemente se realizaron actividades extractivas y de procesamiento de alimentos, que tuvo un rol importante en la redistribución de la cerámica del valle (Terraza 2020). 


\section{Santa Elena}

Descrito primeramente por Rusconi (1962), se trata de un sitio a la orilla del camino, situado a unos 4,5 km del centro de la villa de Uspallata, compuesto por tres rocas grabadas. Schobinger (1971) dio cuenta de solo dos bloques grabados, uno que contiene en forma extrema 'el estilo curvilíneo irregular' y otro muy afectado por agentes naturales. Asoció este registro a un antiguo camino indígena, también ocupado durante épocas coloniales, que cruzaba la precordillera.

En la actualidad se encuentran ambos bloques con graves problemas de conservación (Hart 2009a). En el soporte de mayor tamaño, se estima en treinta el mínimo número de figuras, distribuidas en cuatro sectores del panel.

El otro soporte se ubica a menos de $5 \mathrm{~m}$ del primero, es más pequeño y los grabados, dispuestos sobre el panel noroeste, pueden apreciarse desde el camino ya que la superficie está intensamente grabada (hay registro de superposiciones y yuxtaposiciones) y las figuras presentan gran contraste con la pátina. Se registraron al menos 60 figuras, en su mayoría motivos curvilíneos y circulares, que corresponden al bloque destacado por Schobinger, dado que se observa una forma extrema de lo que él llama estilo curvilíneo irregular. También se relevaron motivos que darían cuenta de la manufactura en el sitio durante el periodo de ocupación incaica en el valle, como cruces inscritas y figuras cuadrangulares con cuatripartición, similares a los signos escudo descritos para los valles centrales chilenos (Troncoso 2008).

\section{Las Bóvedas}

En las inmediaciones de esta instalación dominica de tiempos coloniales vinculada a la explotación minera, se hallaron restos óseos de un individuo con ajuar consistente en una jarra y numerosas cuentas de collar (Rusconi 1962). Por su parte, el autor recolectó al norte del sitio fragmentos de cerámica alisada, conanas, moletas y una piedra con surcos longitudinales, que podría haber servido para enderezar astiles de flecha.

\section{Los Sauces}

Se ubica sobre la margen occidental del arroyo Uspallata, al norte del sitio Las Bóvedas. En la actualidad la zona se presenta intervenida con cultivos, alamedas y el caserío. Este sitio presentó en su superficie cerámicas con y sin decoración, de estilo Inca mixto local y probablemente, Agrelo. Además, se hallaron puntas de flecha, cuentas de collares hechas con cáscaras de moluscos, arte mueble, molinos de piedra, conanas, huesos quemados y fogones (Rusconi 1962; Schobinger 1971).

\section{Uspallata Norte y Tunduqueral Norte}

El yacimiento Uspallata Norte se trata de una distribución densa de material a lo largo del arroyo Uspallata que se extiende desde el límite septentrional de la zona forestada de la villa de Uspallata hasta más al norte del Cerro Tunduqueral. Contiene puntas de proyectil y tiestos no decorados, incisos y pintados, entre ellos el estilo Aguada, pero sin los estilos Diaguita, Inca ni elementos históricos, y cientos de instrumentos de molienda (Rusconi 1962:229-232; Schobinger 1971:77; Lagiglia 2005:51). Las prospecciones sistemáticas iniciales fueron realizadas como parte de un diagnóstico y plan de manejo en el 2010 (Durán et al. 2010, 2012a; Zárate Bernardi 
et al. 2019). Sobre una superficie de $11 \mathrm{~km}^{2}$ que cubre parte de Uspallata Norte y también los alrededores del Cerro Tunduqueral, se identificaron 715 puntos con material arqueológico, en su mayoría materiales líticos aislados, pero también concentraciones líticas, material cerámico y de molienda, fogones y cáscara de huevo de ñandú (Durán et al. 2012a), las cuales son más frecuentes más cerca al arroyo (figura 5). Estas tareas fueron continuadas por dos escuelas de campo (Marsh et al. 2021).

El sector norte de Uspallata Norte se denomina Tunduqueral Norte. Las excavaciones mostraron una ausencia de material estratificado, lo que sugiere que los procesos tafonómicos han dejado como palimpsesto superficial casi todo el material arqueológico (Buehlman-Barbeau et al. 2017). Esta interpretación se apoya en los fechados de dos fogones superficiales asociados con concentraciones mayores de material, con medianas de 450 y 570 cal d.C. (Marsh et al. 2021). Con los datos disponibles, parece que estos fechados indican de manera aproximada la depositación de la mayoría del material superficial; la presencia mínima de cerámica Aguada indicaría un posible uso unos siglos posteriores. También sugiere algún tipo de contacto con grupos de más al norte que también usaron cerámica del mismo estilo, por ejemplo, en el sur de San Juan. Esta misma zona también cuenta con una alta densidad espacial de motivos rupestres Aguada (García 2016), algo notablemente ausente en el valle de Uspallata y la provincia de Mendoza. De todas formas, se puede especular que los petroglifos del Cerro Tunduqueral se hicieron durante la ocupación de Uspallata Norte en el período Medio, a juzgar por los dos fechados superficiales y la escasa presencia de cerámica Aguada.
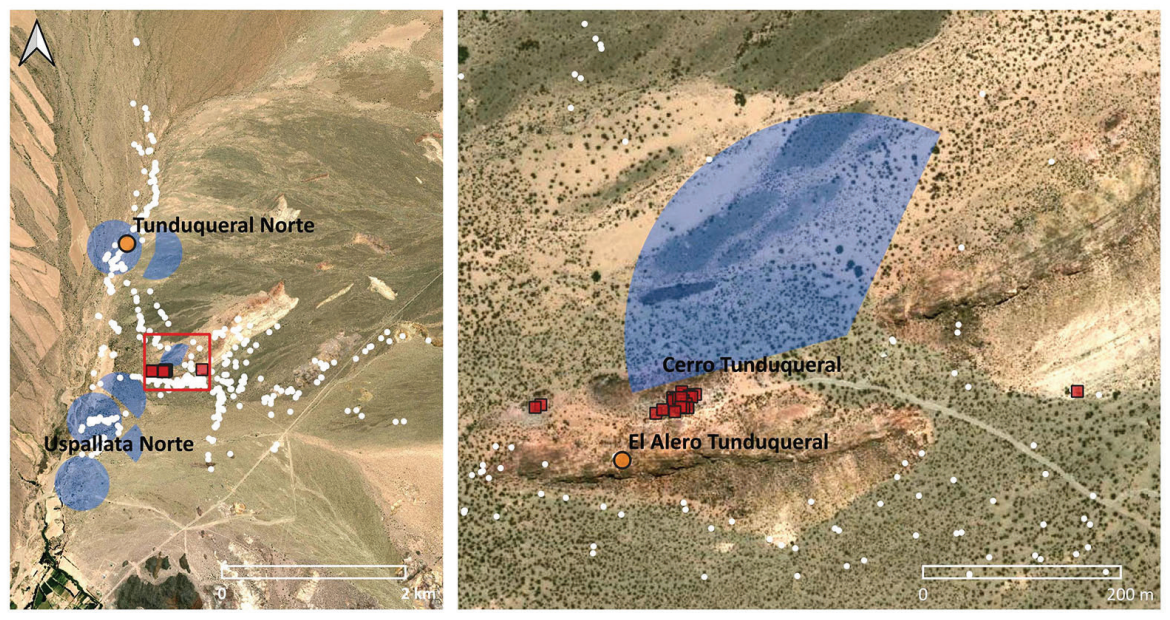

Figura 5. Localización de Uspallata Norte, Tunduqueral Norte, Cerro Tunduqueral y Alero Tunduqueral. Puntos blancos: hallazgos aislados y concentraciones de materiales. Polígonos: límites de prospección con análisis en curso. Cuadrados pequeños: soportes de arte rupestre. El cuadrado en el mapa a la izquierda indica la extensión del mapa a la derecha

\section{Cerro y Alero Tunduqueral}

Schobinger (2009b) relevó el arte rupestre del Cerro Tunduqueral en 1957 y caracterizó varios petroglifos, a los que describe como motivos simbólicos que incluyen una máscara. Aunque no llevó a cabo un relevamiento sistemático de la totalidad del registro rupestre, se basó en comparaciones regionales estilísticas y en interpretaciones realizadas a partir de analogías etnográficas para ubicar la producción del arte en el Periodo Medio. Actualmente, es el sitio con mayor concentración de paneles rocosos grabados del noroeste de la provincia: cuenta con alrededor de 400 
grabados repartidos en veintidós soportes, y ha sido objeto de varias publicaciones, tanto desde la investigación arqueológica como desde aspectos ligados a lo patrimonial, dado que es un lugar disputado por múltiples actores (Bárcena 1991; Ataliva 2001; Hart 2009b, 2016; Zárate Bernardi 2017; Zárate Bernardi et al. 2019) (figura 5).

En cuanto a las interpretaciones acerca de los grabados, se ha postulado que al menos uno de los tres estilos identificados corresponde a la época de dominación incaica en el valle, reflejando relaciones de dominación simbólica respecto a las manifestaciones locales anteriores (Zárate Bernardi 2017; Zárate Bernardi et al. 2020).

Se realizaron excavaciones en el Alero Tunduqueral, un reparo rocoso al suroeste del grupo principal de soportes rupestres (Durán et al. 2010) (figura 5). La excavación de $1 \mathrm{~m}^{2}$ reveló fogones, material lítico, una presencia mínima de cáscara de huevo de ñandú y una ausencia de cerámica, algo notable considerando las densidades cerámicas a pocos metros en Uspallata Norte. La ocupación principal se ubica cerca de 2240 y 1900 cal. AP, según las medianas de dos fechados de capas carbonosas (Marsh et al. 2021). La secuencia cuenta con interrupciones estratigráficas y, entre ellas, la más llamativa es entre las dos ocupaciones fechadas. Este posible hiato ocupacional parece correlacionarse con uno similar en Agua de La Tinaja (Bárcena 1985:341). Este lapso breve cuenta con pocos datos en el valle de Uspallata, pero con una ocupación intensa de las zonas bajas al este, la cual podría interpretarse como un desplazamiento de la población (Marsh et al. 2021).

\section{Petroglifo del Peñón}

Schobinger (1971) lo describe como un petroglifo aislado, posiblemente una máscara, también relevada por Rusconi (1962). Se trata de un sitio compuesto por un único panel grabado que forma parte de un peñón de ignimbrita. Si bien la ubicación de dicho peñón es conocida y visitada por muchos ya que en él se emplazan grutas de varios santos, las figuras grabadas se mantienen bien conservadas. Ubicadas en el sector suroeste de la geoforma y orientadas hacia ese punto cardinal, son escasamente visibles dado que los surcos son finos y apenas profundos, lo que genera poco contraste con la pátina. Son dos figuras, una es un mascariforme de tamaño menor a las registradas en otros sitios del valle y la otra es un cuadrangular que, según la descripción de Rusconi (1938-39) recuerda "la figura de una habitación indígena".

\section{Tambillos}

Este tambo incaico fue reconocido por Rusconi (1962), mencionado por Schobinger (1971) y por Hyslop (1984) y estudiado por Bárcena y equipo en la década de 1980. Se distinguieron tres sectores con estructuras arquitectónicas de muros construidos con hileras dobles de piedra. El sector I presenta un rectángulo perimetral compuesto (RPC), un recinto cuadrangular y una colca, el sector II un patio y habitaciones abiertas a éste y el sector III un taller cerámico (figura 6).

Las excavaciones en el RPC mostraron que algunos de los espacios amplios interiores fueron patios donde se prepararon alimentos y conformaron artefactos, en tanto que varios de los recintos menores adosados sirvieron de habitaciones (Bárcena 1993), por lo que fue interpretado como una kancha. Por su parte, el recinto cuadrangular fue asemejado a una plaza intramuros con funcionalidad ceremonial y/o de uso público, así como al denominado recinto "b" se lo catalogó como espacio de almacenamiento o colca.

En el segundo sector se observaron fogones y materiales cerámicos, líticos y zooarqueológicos, producto de actividades relacionadas a la cocción de alimentos y a la preparación de artefactos. Una parte de los tiestos corresponderían a estilos cerámicos foráneos, en particular, 


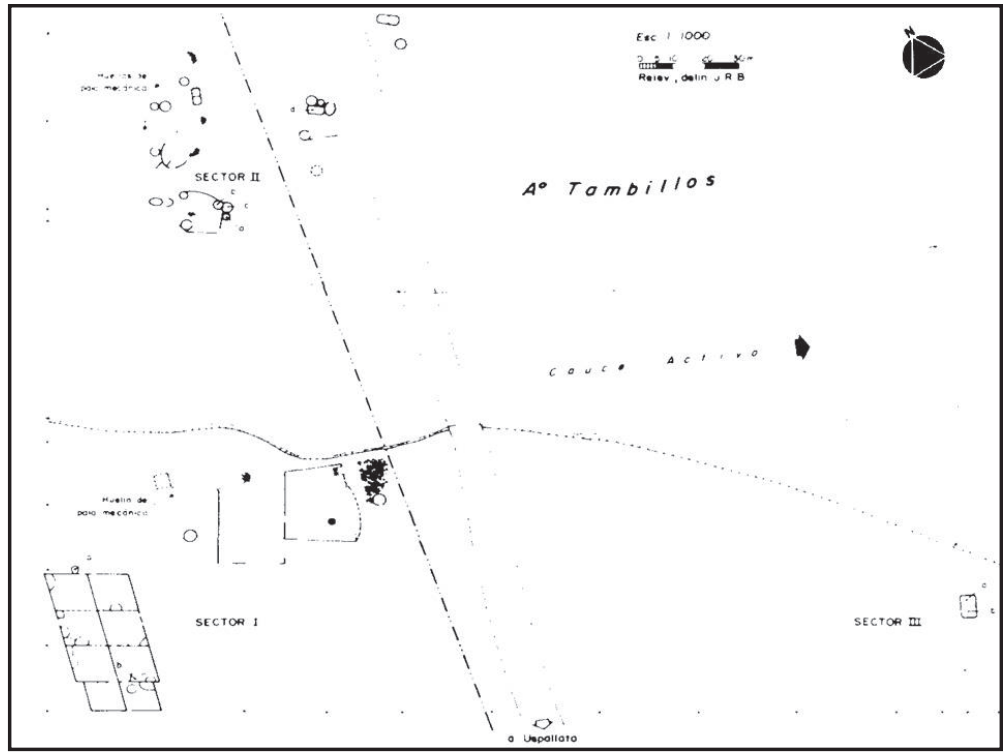

Figura 6. Planimetría del sitio Tambillos. Extraído y modificado de Bárcena (1988)

al diaguita chileno fase Inca, y otra parte estaría representada por un estilo de producción local, con influencia cuzqueña. El análisis lítico se hizo sobre puntas de proyectil y se determinó el predominio de formas isósceles, sobre sílice y cuarzo, de tamaños pequeños, apedunculadas y con bases cóncavas. El mayor porcentaje de huesos animales identificados corresponden a camélidos (García Llorca 1995).

En el sector III se encontraron pisos consolidados arcillosos, varios fogones, restos óseos de auquénidos y de aves (quemados o no), puntas de proyectil, fragmentos de valvas de molusco, cuentas de collar, pulidores-alisadores para cerámica, fragmentos de arcilla y de piedra pómez y fragmentos de grandes vasijas tipo aríbalos. Esto permitió sugerir que el espacio "fue para la manufactura de cerámica -en particular grandes recipientes, adecuados para almacenamiento-, por artesanos regionales según patrones incaicos" (Bárcena 1988:415).

Entre los fragmentos decorados se reconocieron algunos asimilables al estilo diaguita chileno fase inca, tanto por su decoración como por sus formas. Se mencionan una "escudilla honda de paredes entalladas", vasijas "restringidas" y un plato. El conjunto llevó a Bárcena (1988) a proponer que el sitio fuera ocupado por mitmaqunas del Norte Chico chileno.

Además, se hallaron otros tipos cuya forma y decoración siguen modelos incaicos, aunque su manufactura se aprecie como regional, como el caso de platos con apéndices ornitomorfos, aribaloides con decoraciones geométricas y un fragmento discoidal perforado en el centro. Tres fragmentos de platos, que se asemejan al estilo Inca-Pacajes, podrían reflejar la movilización de maestros artesanos provenientes del Altiplano boliviano, cuyas funciones habrían estado destinadas a dirigir y organizar ciertas actividades de importancia para la distribución y redistribución del incario, como la producción cerámica en manos de ceramistas locales (Bárcena y Román 1990). También es factible que la presencia de esta cerámica refleje redes de intercambio.

\section{Ranchillos}

Se trata de la implantación incaica de mayor envergadura en el norte de Mendoza, de 6.600 
$\mathrm{m}^{2}$, tanto desde la planificación arquitectónica como por reunir la mayor superficie construida. Los últimos trabajos arqueológicos sistemáticos sobre el sitio fueron abordados hace dos décadas, con continuidad de aportes (Bárcena 1998 a y b, 2020), precedidos por los de Aparicio (1940) y Rusconi (1940, 1956, 1962). Al estudio arquitectónico, se sumaron análisis de materiales cerámicos, líticos, óseos, antracológicos y de restos botánicos (en paleo-deyecciones de roedores).

Respecto a los rasgos arquitectónicos se presentan cuatro RPCs, una plaza intramuros, varias estructuras simples aisladas, dos kanchas semicirculares y un conjunto de estructuras simples asociadas que podrían ser corrales y/o habitaciones (figura 7).

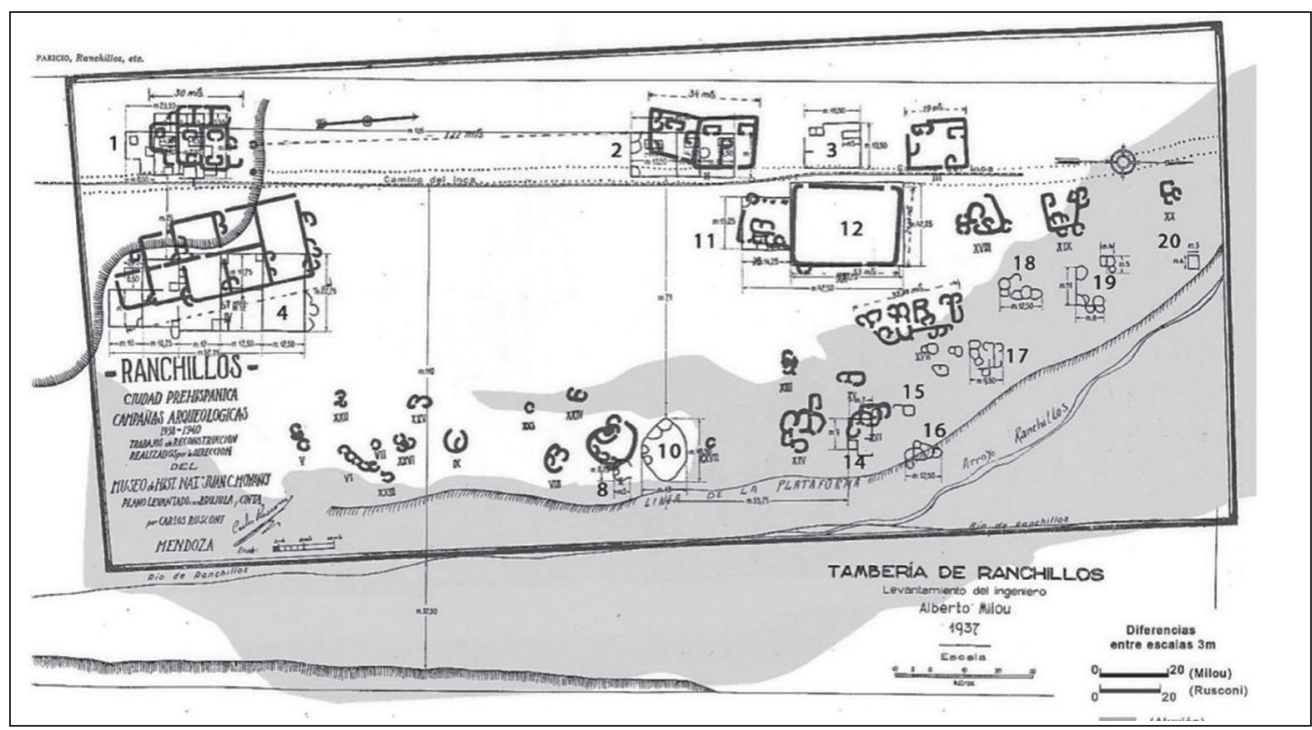

Figura 7. Planimetría del sitio Ranchillos. Extraído de Bárcena (2021). Rusconi (1956) presenta otras denominaciones de los sectores

De los resultados del análisis cerámico se destaca la alta concentración de fragmentos en el Recinto 3 del RPC; el alto porcentaje de decorados en esta última estructura y su diferenciación en comparación con los tiestos presentes en la plaza intramuros (que destacan por ser menor en número y mayoritariamente sin decoración) o con los procedentes de los recintos de la Unidad E (caracterizados por un número alto de fragmentos para el tambo y por unidad de superficie, con el $85 \%$ de los fragmentos sin decoración) y, además, por el predominio de recipientes cerrados, indicadores de artefactos asociados a la preparación de alimentos, almacenaje, transporte, entre otras actividades, por sobre los abiertos (la mayoría son platos engobados) (Bárcena 1998b).

El análisis lítico se concentró en puntas de proyectil de los recintos 3 y 4 del RPC mencionado, se trata de ejemplares triangulares sobre sílices criptocristalinos y pórfidos, con predominio de piezas apedunculadas y con base cóncava, de tamaño pequeño y muy pequeño. La mayor concentración se encontró en el Recinto 4; se plantea que, dada su particular distribución, podría tratarse de un área de actividad (taller) relacionada a la preparación de este material (Bárcena 1998b).

En estos mismos recintos se rescató una muestra de restos de camélidos, NISP de 48 en Recinto 3 y 93 en Recinto 4. Se menciona, además, la presencia de un "ruki”, artefacto óseo construido con la mitad proximal de un metatarsiano de auquénido adulto, asociado a actividades textiles (Bárcena 1998b).

Se postuló el sitio, en relación con los otros sitios incas de la región, como "Tambo Real" por la suma de "rasgos imperiales" como los RCP y la piedra símil sillar, el revestimiento con revoque de barro, la posibilidad de que existiera "techumbre en caballete" y vanos trapezoidales, 
reforzada por su patrón de instalación, tamaño y jerarquía arquitectónica. Además, se atribuyó una ocupación de población estable y otra en tránsito, cuyos recursos de manutención provendrían del valle de Uspallata (Rusconi 1962:236; Bárcena 1998b).

\section{Tambillitos}

Ubicado a $34 \mathrm{~km}$ al oeste de la villa de Uspallata, se trata de estructuras pircadas entre las cuales hay un RPC y otros recintos interpretados como plazas ceremoniales y corrales (figura 8).

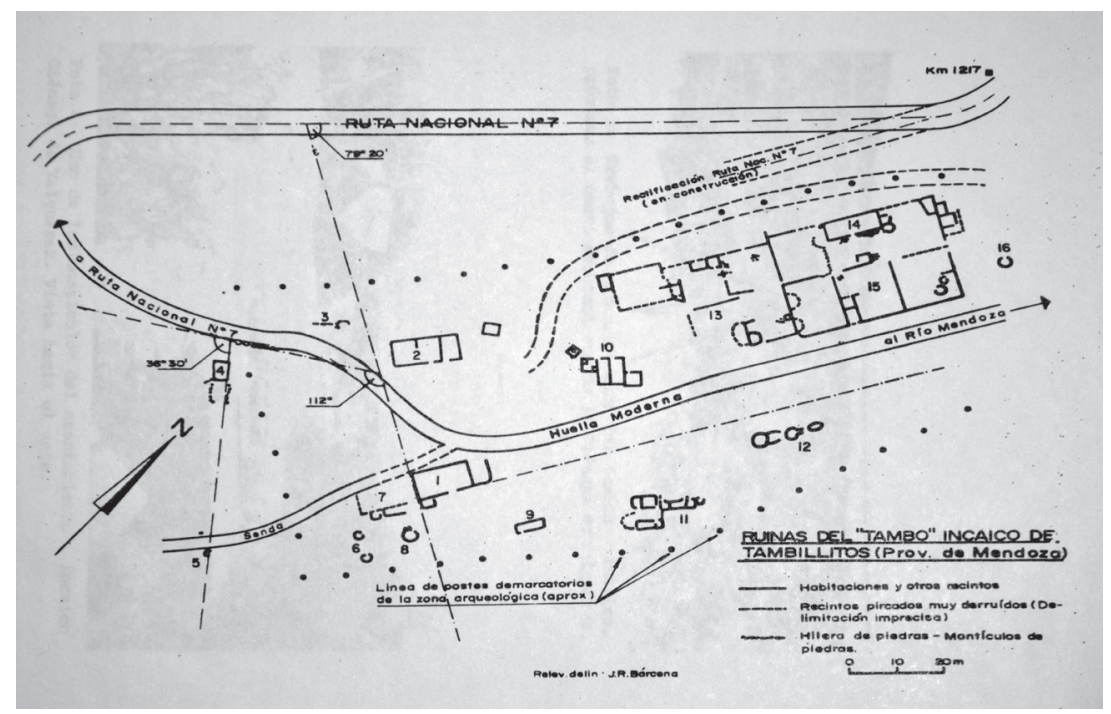

Figura 8. Planimetría del sitio Tambillitos. Extraído de Bárcena (1977)

Las excavaciones en el sitio revelaron una ocupación de un solo grupo cultural durante un lapso breve, que coincidiría con la dominación inca. Se hallaron puntas de flecha triangulares pequeñas de obsidiana o cuarzos; una moleta con pigmento rojo en su cara superior y trozos de minerales pigmentosos (ocres); restos óseos de camélidos asociados a fogones; restos óseos humanos; valvas de molusco (Diplodon sp.) y cerámica con y sin decoración (entre la cual hay tipos grises y marrones alisados).

A partir del análisis de la cerámica decorada se determinó la presencia del estilo Inca Policromo (sensu Rowe 1946), un estilo inca de "variante regional de hechura", cuyos productores provendrían de los centros regionales del incario del Norte Chico chileno o de Chile Central, y algunos fragmentos del "diaguita clásico" y el "cuarto estilo" (Bárcena 1977).

\section{El Chacay}

Se encuentra a la vera del camino incaico al noreste de Ranchillos. Los primeros trabajos arqueológicos realizados en el sitio se remontan a la década de 1980 por parte de Bárcena y su equipo. Pero es en 2017, cuando se hallan estructuras arquitectónicas asociadas a material cerámico con incidencia incaica. Se identificaron una estructura pircada de muro doble y planta circular, con dos recintos (R2 y R3) adosados a uno mayor (R1) y al menos uno de ellos (R2) comunicado con él por una abertura (figura 9). 


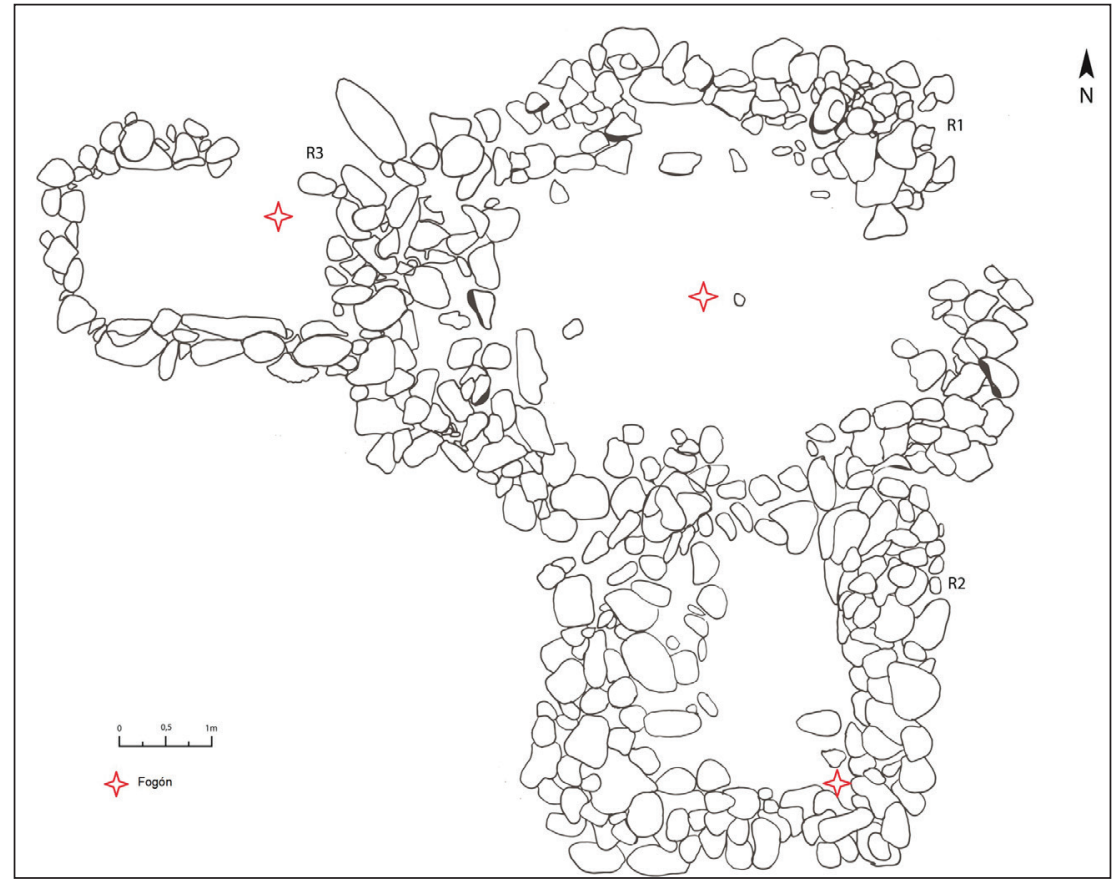

Figura 9. Planimetría del sitio El Chacay. Extraído de Terraza et al. (2019)

Tanto el material lítico como el cerámico se presentaron concentrados en sectores particulares y diferenciados de $\mathrm{R} 1$. El registro cerámico consiste en 86 fragmentos y se trata de platos cuyas características tecnológicas pueden estar vinculadas directamente con tradiciones en las formas de hacer de grupos provenientes del Norte Chico chileno o de Chile Central.

La distribución diferenciada de material lítico respecto al cerámico en R1 podría indicar un uso diferencial del interior del espacio residencial, de acuerdo a actividades y prácticas cotidianas. Por otro lado, el hecho de que los materiales arqueofaunístico y arqueobotánico aparezcan asociados a fogones, pero en otros recintos ( $\mathrm{R} 3$ y $\mathrm{R} 2$ ) diferentes a $\mathrm{R} 1$ podría denunciar que estos fueron utilizados para preparar y cocinar los alimentos (R1 presentó una estructura de combustión sin asociaciones a evidencias de consumo de comida). La presencia de un solo paquete estratigráfico que coincide con el piso de ocupación del sitio donde se encuentran los fogones, los restos arqueológicos asociados y el arranque de los muros, permite generar la hipótesis de que la construcción del sitio habría sido temporalmente cercana al episodio de uso y/o descarte de los materiales hallados que, a su vez, indicarían una asociación con la presencia incaica en el valle. El fechado ${ }^{14} \mathrm{C}$ de R3 tiene una mediana de 1430 cal d.C. (Terraza et al. 2019).

\section{Barrio Ramos}

Ubicado dentro de la villa de Uspallata, el sitio es un enterratorio múltiple que incluye tres subadultos y tres adultos acompañados de ajuares mortuorios (Bárcena 1998a). Recientemente, Durán et al. (2018:64) observaron que dos de los individuos adultos tienen indicadores traumáticos. El ajuar funerario comprende vasijas cerámicas, puntas de proyectil líticas y óseas, cuentas de collar sobre valvas de moluscos y de Diplodon sp., espátulas y retocadores de hueso, entre otros. Los fechados del entierro muestran que el sitio es coetáneo con la presencia inca (Gil et al. 2014; 
Marsh et al. 2017; Durán et al. 2018). Los últimos autores interpretan a estos individuos como de rango elevado dentro de los grupos locales de Uspallata, con evidencias que sugieren que no fueron migrantes ni de poblaciones trasladadas por el imperio inca en calidad de mitmaqunas.

\section{Qhapaq Ñan, red vial incaica}

El camino incaico en la microrregión, aún visible en algunos sectores, proviene desde el valle de Calingasta y penetra al valle de Uspallata, para salir por el cajón del río Mendoza hasta Chile (Schobinger 2009a). Los sitios incaicos ligados al camino, de norte a sur, son: Yalguaraz, Tambillos, Ranchillos y Tambillitos, estos últimos tres responderían a las categorías de "tambos" o "tambillos" (Bárcena 1998b). Además, hay evidencias materiales incas en Confluencia (Bárcena 2001) y en cerro Aconcagua (Schobinger 2001). Los tambos se encuentran distanciados regularmente de 22 a $25 \mathrm{~km}$ unos de otros, distancia que coincidiría con los recursos hídricos disponibles, la topografía del terreno por la que transcurre el camino y su funcionalidad de "posadas" o "lugares para dormir" (Bárcena 1993).

Las características del trazado se modifican de acuerdo a cada tramo observado. En el tramo que une a Yalguaraz y San Alberto, por ejemplo, se trata de una senda despejada (Sosa et al. 2020). Entre Tambillos y San Alberto mide alrededor de $3 \mathrm{~m}$ de ancho, medida que puede variar y alcanzar los 5-6,5 m en algunos segmentos. Además, cuando atraviesa cauces secos, presenta a ambos lados un muro bajo o hilera de piedras, e incluso un escalonado (Bárcena 1988:417). La presencia de mojones en los márgenes del camino fue registrada en el trecho que media la Pampa del Chacay con San Alberto (Rusconi 1962:253). En el tambo de Ranchillos, por su parte, el camino tiene de 3 a $5 \mathrm{~m}$ de ancho y combina segmentos despejados con amojonados (Rusconi 1962:252).

\section{DISCUSIÓN}

Del análisis de la publicación de 1971 se desprende una serie de cuestionamientos y críticas que buscan reconsiderar las formas de abordar problemas arqueológicos en el pasado de nuestra disciplina.

Uno de los aspectos clave desarrollados por Schobinger fue el planteo de una periodización para el valle de Uspallata. Los intereses disciplinares estaban centrados en la agrupación de artefactos por rasgos diagnósticos y de distribución geográfica restringida, y su ubicación en el interior de moldes culturales, los cuales respondían a un paradigma teórico-metodológico típico de la época: el enfoque histórico-cultural. Hoy se cuestionan estas macrosecuencias extrapoladas del NOA al COA, debido a la dificultad de semejar esos procesos con los modos de vida de los grupos locales. Su uso llevó a uniformar el entendimiento del poblamiento humano de este espacio, dejando implícito que los procesos económicos, sociales, políticos y simbólicos de las sociedades aldeanas que se desarrollaron durante la etapa cerámica hasta la dominación inca no cambiaron demasiado (Durán et al. 2006). Los períodos de esta etapa fueron diferenciados por el desarrollo de "culturas" cuyos modos de vida habrían sido homogéneos y se habrían distinguido principalmente por una supuesta presencia/ausencia de determinados rasgos arqueológicos, principalmente, tipos cerámicos que fueron identificados a partir de atributos muy generales (formas, decoración y tratamientos de superficie).

Se considera que actuales y futuros esfuerzos podrán superar las limitaciones de la historia cultural al (1) intentar separar las tendencias cerámicas y otros patrones materiales, (2) considerar la posibilidad de un momento con poca ocupación o sin cerámica diagnóstica y (3) dejar abierta la probabilidad de fases que mostrarían una reducción en la complejidad social, quizás con mayor movilidad y sin cultígenos y/o cerámica. 
Otra característica del artículo es la escisión presente entre las variables espacio-tiempo, por la cual se enmarcan los sitios arqueológicos a partir de características geográficas generales acotadas, para luego describirlos y adjudicarles una temporalidad determinada, sin establecerse relaciones entre los escenarios y factores ambientales y los procesos sociales. En las siguientes décadas, el desarrollo de marcos teóricos funcionalistas, marxistas, ambientales, ecológicos, procesuales, entre otros, han permitido la generación de nuevas preguntas y respuestas de investigación, en donde los artefactos pierden protagonismo y la adaptación al entorno de los grupos humanos adquiere relevancia.

En la actualidad, las nuevas concepciones sobre el paisaje arqueológico permiten ir más allá de la dualidad espacio-tiempo y visualizar el conjunto de sitios del valle de Uspallata como una red poli-espacial de lugares atravesados por la variable temporal, donde se realizaron actividades varias, integradas o no entre sí, que: (a) tenían relación con la muerte y su culto; (b) estaban vinculadas a prácticas ceremoniales y simbólicas; (c) tenían una función político-administrativa; (d) formaban espacios residenciales; (e) constituían espacios de obtención y/o producción de alimentos; (f) eran fuentes de materias primas para la realización de productos manufacturados; (g) instituían espacios donde se producían manufacturas y (h) conformaban vías de circulación de agentes (personas, animales y cosas).

Consideramos imprescindible relacionar estos espacios físicos/percibidos (en términos de Lefebvre 1974) con su entorno ambiental, al notar que la mayoría de los sitios tempranos se hallan localizados al norte, en el área del Arroyo del Tigre, en las cercanías a la Ciénaga de Yalguaraz (Bárcena 1978, 1982) y al noreste del valle, en el entorno de precordillera, como Agua de la Cueva (Durán y García 1989; Castro y Yebra 2018), Agua de la Zorra (Cortegoso et al. 2017) y Paso de Paramillos (Bárcena 1998a), entre otros. Los lugares del habitar integrarían circuitos amplios de movilidad y coincidirían con una economía cazadora-recolectora.

Esta situación se ve modificada con el tiempo cuando comienza a ocuparse de forma más permanente la zona de Uspallata Norte primero y el fondo de valle después, con el desarrollo de prácticas hortícolas y agrícolas, la reducción de la movilidad, el aumento demográfico y, más tardíamente, la presencia de cerámica. Se suman evidencias de domesticación de camélidos en la zona de precordillera.

Serán los ambientes pedemontano y de la Cordillera del Tigre los últimos en agregarse a la red de sitios, vinculados a los procesos del dominio incaico regional. Es fundamental en este ensamblaje y asociación de lugares el rol del Qhapaq ñan en la conformación del paisaje del entorno cordillerano, además de la instalación de sitios de altura (Contrafuerte Pirámide, Confluencia, Penintentes) que, si bien están por fuera del valle, forman parte del mismo entramado. En el propio valle, esta dominación se sostendrá a partir de la instalación de infraestructura arquitectónica y caminera, pero también de materialidades presentes en sitios que sobresalen del control directo ejercido en el entorno cordillerano, como lo evidencian hallazgos en La Chanchería, Barrio Ramos I, Cerro Tunduqueral, Petroglifos de Santa Elena, entre otros.

Por otra parte, el artículo de Schobinger muestra matices difusionistas observados en la clasificación de materiales con "aires" o "del tipo" chileno, inca, araucano, etc. No resulta extraño, por ende, que el autor plantee la posibilidad de migraciones provenientes del NOA y/o del Norte Chico y Chile Central para explicar la presencia de materialidades cuyo origen parece ser foráneo al valle (Schobinger 1971:82; Bárcena 1988).

A la luz de las nuevas investigaciones, en la actualidad estimamos que el panorama y la dinámica ocupacional del valle habría sido más compleja y variante, que existieron relaciones transcordilleranas desde tiempos remotos, así como redes de conexión con las planicies y las llanuras de la vertiente oriental y vínculos con el NOA y el altiplano boliviano. Planteamos, además, la recurrencia de grupos móviles regionales que interactuaron con los pobladores del valle, con fines específicos. En este sentido se puede mencionar la hipótesis de la procedencia foránea de la cerámica gris de Uspallata, producida por artesanos itinerantes del valle de Potrerillos (Terraza 
2020). Por último, se habrían instalado grupos de migrantes en la microrregión, generando un contexto social diverso que luego interactuó con agentes incaicos en la conexión con otros sitios del imperio inca (Barberena et al. 2020).

Un último aspecto por mencionar, y no por ello de menor importancia, es el valor insustituible de la sistematización ordenada y rigurosa de los sitios del valle realizada por Schobinger, al tener en cuenta las modificaciones ocurridas sobre el paisaje, cuya fisonomía ha cambiado de modo considerable en estos cincuenta años. Gracias a ese registro, hoy podemos trazar líneas explicativas para los procesos de uso/preservación/destrucción de los sitios. La descripción realizada ilustra este desarrollo: la mayoría de los sitios emplazados en el fondo del valle y en el piedemonte ha desaparecido parcial o totalmente. Esta metamorfosis se sustenta fundamentalmente en las acciones antrópicas, como observamos por ejemplo en La Chanchería, cuyo marco espacial se ha visto alterado en la última década por los barrios aledaños, los caminos diseñados, la traza de una pista de carreras de caballos, el alambrado de propiedades privadas, la remoción de suelos para establecer un área municipal de deportes y por el cultivo de sus tierras. Otros dos casos de modificación paisajística lo constituyen los sitios Petroglifos de Santa Elena y Cerro Tunduqueral. En las cercanías del primero se ha erigido una gruta dedicada a un santo popular, el Gauchito Gil. El accionar del público visitante ha consistido en pintar con aerosol en varias ocasiones las rocas-soporte de los petroglifos y en remover la pátina casi en su totalidad. En tanto que en Cerro Tunduqueral la acción antrópica data de varias décadas atrás cuando una empresa contratista del Estado dinamitó y extrajo rocas del cerro para obras de infraestructura caminera, situación que entonces pudo ser denunciada y frenada (Bárcena 1991, 2018; Zárate et al. 2019). Sin embargo, hace pocos años los grabados fueron nuevamente expuestos a la degradación intencional, al arrojarse a uno de sus paneles pintura amarilla (figura 10). Los sitios ubicados en
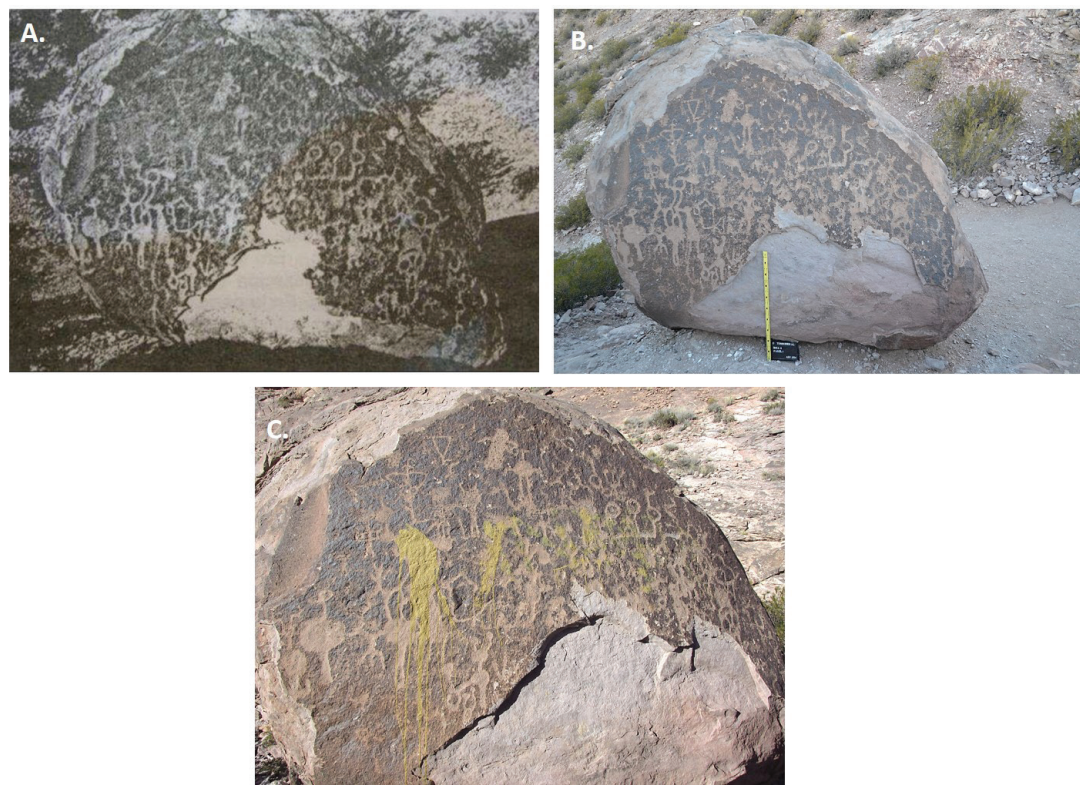

Figura 10. Fotografías del soporte, panel 1 de Cerro Tunduqueral (sensu nomenclatura en Zárate Bernardi 2017). Se observa el deterioro de los grabados y del propio soporte producto de la acción antrópica intencional: A. Según Schobinger, las roturas en el panel fueron realizadas deliberadamente en 1971 (tomada por Eduardo Ripoll, en Schobinger 2009a [1982]: 77; Figura 9); B. Fotografía tomada en 2010, durante la realización del relevamiento para el Plan de Manejo del sitio (Durán et al. 2010), se percibe cómo ha aumentado la dimensión del sector que falta en el panel; C. Daños voluntarios con pintura sobre el mismo soporte (Autoría: Sol Zárate Bernardi) 
el sector cordillerano también han sufrido modificaciones tanto de origen humano como natural, destacándose entre estas últimas los daños provocados por un aluvión en el año 2018 en algunos recintos del sector septentrional del tambo de Ranchillos (figura 7).

\section{CONCLUSIONES}

Las labores de investigación de Juan Schobinger en el valle de Uspallata marcaron un antes y un después en la arqueología del COA. Cincuenta años después, la lectura de los implícitos teórico-metodológicos de su síntesis preliminar de la arqueología del valle de Uspallata nos permite un acercamiento y comprensión del continuum disciplinar regional.

Con consciencia de esa variación en los abordajes, interrogantes, métodos y técnicas analíticas durante este tiempo transcurrido, lo sometimos a revisión y actualización. Observamos avances generales en la producción de información cronológica, a partir de la introducción, desarrollo, diversificación y especialización de las técnicas analíticas utilizadas, destacándose tanto el análisis arquitectónico y de materiales lítico, óseo y cerámico, como los recientes estudios bioarqueológicos, de isótopos estables y del arte rupestre. Además, las investigaciones progresaron en la generación de información arqueológica y ambiental sobre los entornos de precordillera y de la zona norte del valle; la profundización de los datos arqueológicos, sumados al estudio etnohistórico, acerca del dominio incaico y su relación con las poblaciones tardías del valle; y en la indagación del arte rupestre del valle y de las zonas altas cercanas, en persistencia con los intereses del autor examinado.

A los trabajos de investigación desarrollados, se suman hoy las tareas de protección y conservación patrimonial de los sitios, las cuales urgen necesarias e imprescindibles ante los procesos de deterioro, destrucción y/o desaparición del registro arqueológico del valle.

\section{AGRADECIMIENTOS}

Agradecemos a Roberto Bárcena y a Víctor Durán por su compromiso en la lectura y revisión del escrito. Las investigaciones han sido financiadas por proyectos de SIIP-UNCuyo y por CONICET.

\section{REFERENCIAS BIBLIOGRÁFICAS}

Aparicio, F. de (1940). Ranchillos. Tambo del inca en el camino a Chile. Anales del Instituto de Etnografía Americana I: 245-253.

Ataliva, V. (2011). Diagnóstico para la conservación y agentes de valoración: las representaciones rupestres del Cerro Tunduqueral (Uspallata, Mendoza). San Miguel de Tucumán, Universidad Nacional de Tucumán.

Barberena, R., L. Menéndez, P. J. le Roux, E. J. Marsh, A. Tessone, P. Novellino, G. Lucero, J. Luyt, J. Sealy, M. Cardillo, A. Gasco, C. Llano, C. Frigolé, D. Guevara, G. Da Peña, D. Winocur, A. Benítez, L. Cornejo, F. Falabella (...) V. Cortegoso (2020). Multi-isotopic and morphometric evidence for the migration of farmers leading up to the Inka conquest of the southern Andes. Sci Rep 10, 21171. https://doi.org/10.1038/ s41598-020-78013-x

Barberena, R., A. Tessone, P. Novellino, E. Marsh, V. Cortegoso, A. Gasco, D. Guevara y V. Durán (2021). Esferas de movilidad, sistemas de parentesco e isótopos: una exploración comparativa desde el norte de Mendoza. Ms. DOI: 10.13140/RG.2.2.22221.77283 
Vanina V. TerRaza y otros - Arqueología del valle de Uspallata (NO de Mendoza): una síntesis ...

Bárcena, J. R. (1974-76a). Antropología física del Valle de Uspallata, Provincia de Mendoza. Anales de Arqueología y Etnología XXIX-XXXI: 109-184.

Bárcena, J. R. (1974-76b). Análisis químico y metalográfico de los elementos del ajuar funerario de UspallataUsina- Sur. Anales de Arqueología y Etnología XXIX-XXXI: 91-107.

Bárcena, J. R. (1977) [1979]. Informe sobre recientes investigaciones arqueológicas en el N.O. de la Provincia de Mendoza-Argentina (Valle de Uspallata y zonas vecinas) (Con especial referencia al período incaico). Actas del VII Congreso de Arqueología de Chile II: 661-692. Santiago de Chile. Ediciones Kultrun.

Bárcena, J. R. (1978). Investigaciones arqueológicas en el N.O. de la provincia de Mendoza (Con especial referencia al Período Precerámico). Anales de Arqueología y Etnología XXXII-XXXIII: 75-172.

Bárcena, J. R. (1982). Sinopsis de investigaciones arqueológicas en el N.O. de la provincia de Mendoza: secuencias estratigráficas y cronología absoluta. Boletín del Museo Ciencias Naturales y Antropología "Juan Cornelio Moyano" 3: 65-81.

Bárcena, J. R. (1988). Investigación de la dominación incaica en Mendoza. El Tambo de Tambillos, la vialidad anexa y los altos cerros cercanos. Espacio, Tiempo y forma: Revista de la Facultad de Geografía e Historia, Serie I, Prehistoria 1: 397-426.

Bárcena, J. R. (1991). La Protección del patrimonio arqueológico. Programa Provincial de Montaña. Subsecretaría de Deportes. Gobierno de Mendoza. Mendoza.

Bárcena, J. R. (1992). Datos e interpretación del registro documental sobre la dominación incaica en Cuyo. Хата 4-5: 11-49.

Bárcena, J. R. (1993). Protección de sitios arqueológicos en el área de montaña mendocina. El Tambo y camino incaico de Tambillos (Valle de Uspallata, N. O. de Mendoza, Argentina). Mendoza. PRODAM.

Bárcena, J.R.(1998a). Arqueología de Mendoza. Las dataciones absolutas y sus alcances. Mendoza. EDIUNC.

Bárcena, J. R. (1998b). El Tambo Real de Ranchillos, Mendoza, Argentina. Xama 6: 1-52.

Bárcena, J. R. (1999). Contribución a los estudios interdisciplinarios, arqueológicos y etnohistóricos, sobre la dominación inka en el centro-oeste argentino. Actas del XII Congreso Nacional de Arqueología Argentina I: 163-178. Facultad de Ciencias Naturales y Museo, Buenos Aires.

Bárcena, J. R. (2001). Prehistoria del Centro-Oeste argentino. En E. Berberián y A. Nielsen (eds.), Separata de Historia Argentina Prehispánica II: 561-614. Córdoba. Editorial Brujas.

Bárcena, J. R. (2004). Gestión de recursos culturales arqueológicos en el norte de la provincia de Mendoza (República Argentina): Algunas experiencias de trabajo. Chungara Revista de Antropología Chilena 36(1): 499-508.

Bárcena, J. R. (2010). Investigaciones arqueológicas en la Tambería de Guandacol (Departamento Felipe Varela, provincia de La Rioja). En J. R. Bárcena, Arqueología del Centro Oeste Argentino. Aportes desde las IV Jornadas Arqueológicas Cuyanas. Serie Monografías Xama 2. Mendoza. INCIHUSA-CONICET.

Bárcena, J. R. (2011). Arqueología en el valle de Uspallata. Diario Los Andes, 17 de julio de 2011.

Bárcena, J. R. (2013). Grabados rupestres del área de la Quebrada de La Chilca, vertiente occidental de la Sierra de Valle Fértil, provincia de San Juan, Argentina. El sitio La Chilca Pintada. Anales de Arqueología y Etnología 65-67: 89-120. 
Bárcena, J. R. (2018). Patrimonio: siguen en riesgo grabados rupestres del cerro Tunduqueral. Nota en Diario Los Andes, 6 de enero de 2018.

Bárcena, J. R. (2020). A ochenta años de Anales del Instituto de Etnografía Americana y de las Publicaciones sobre el Tambo de Ranchillos, hasta nuestras investigaciones en el sitio. Salvador Canals Frau, Carlos Rusconi y Francisco de Aparicio en contexto de época. Octogenario dicata. Serie Monografías 6. Xama. Mendoza.

Bárcena, J. R. y M. Dacar (1999-2001). Estudio de deyecciones fósiles de roedores del área de montaña del noroeste de Mendoza (Argentina). Análisis de contenidos de nidos y estercoleros de la rata chinchilla, Abrocoma sp., como posibles indicadores biológicos paleoambientales en el sitio del Tambo Real de Ranchillos. Xama 12-14: 1-47.

Bárcena, J. R., F. Roig y V. Roig (1985). Aportes arqueo-fitozoológicos para la prehistoria del NO de la provincia de Mendoza: la excavación de Agua de la Tinaja I. Trabajos de prehistoria 42: 311-363.

Bárcena, J. R. y A. Román (1990). Funcionalidad diferencial de las estructuras del tambo de Tambillos: resultados de la excavación de los recintos 1 y 2 de la Unidad A del Sector III. Anales de Arqueología y Etnología XL-XLI: 7-81.

Bárcena, J. R., Terraza, V. y J. P. Aguilar (2017). El Chacay: nuevo sitio incaico en el Qhapaq Nan a Chile. Nota en Diario Los Andes, 9 de diciembre de 2017.

Bárcena, J. R., Terraza, V. y M. L. Iniesta (2015). Estudios tecnoestilísticos y de dataciones TL de materiales cerámicos del sitio La Chanchería (Valle de Uspallata, Noroeste de Mendoza, Argentina). En J. R. Bárcena, (ed.), Arqueología y Etnohistoria del Centro Oeste Argentino. Aportes desde las V Jornadas Arqueológicas Cuyanas. Xama Serie Monografías 5: 95-117. Mendoza. Zeta Editores.

Buehlman-Barbeau, S., K. Carline, De Alba, J. y E. Marsh (2017). The Uspallata Valley Archaeology Project: A Study of the Transition from Foraging to Pastoralism and Agriculture around Cerro Tunduqueral, Mendoza, Argentina. DOI: 10.13140/RG.2.2.36375.57767

Burrieza, H. P., A. Sanguinetti, C. T. Michieli, H. Berteroy S. Maldonado (2016). Death of embryos from 2300-year-old quinoa seeds found in an archaeological site. Plant Science 253: 107-117. DOI:10.1016/j. plantsci.2016.10.001.

Cahiza, P. (1997). La presencia incaica en el noroeste de Mendoza: Análisis y experimentación cerámica. Seminario de Licenciatura inédito. Facultad de Filosofía y Letras. Universidad Nacional de Cuyo.

Cahiza, P. (2003). La dominación inka en las tierras bajas de Mendoza y San Juan. Tesis doctoral inédita. Facultad de Filosofía y Letras, Universidad Nacional de Cuyo.

Cahiza, P. y M. J. Ots (2005). La presencia inca en el extremo sur-oriental del Kollasuyo. Investigaciones en las tierras bajas de San Juan y Mendoza y en el Valle de Uco, Rca. Argentina. Xama 15-18: 217-228.

Castro, S. y L. Yebra (2018). Ocupación tardía de la precordillera de Mendoza: organización tecnológica en Agua de la Cueva Sector Norte (ca. 1700-470 años cal. AP). Anales de Arqueología y Etnología 73, 1: 7-40.

Chiavazza, H. y V. Cortegoso (2004). De la cordillera a la llanura: disponibilidad regional de recursos líticos y organización de la tecnología en el norte de Mendoza, Argentina. Chungara, Revista de Antropología Chilena, vol. 36, núm. 2: 723-737.

Cortegoso, V. (2004). Organización tecnológica: explotación de recursos líticos y el cambio en la subsistencia de cazadores a agricultores en el NO de Mendoza. Tesis de Doctorado inédita. Facultad de Ciencias Naturales y Museo, Universidad Nacional de La Plata. 
Vanina V. TerRaza y otros - Arqueología del valle de Uspallata (NO de Mendoza): una síntesis ...

Cortegoso, V., G. Lucero, S. Castro y D. Winocur (2017). Bosques fósiles y tecnología humana: la explotación de materias primas líticas en el Bosque de Darwin, Paramillos (Argentina). Latin American Antiquity 18: 317-337.

Da Peña, G., P. Novellino y C. Frigolé (2016). Caracterización del Túmulo II (Uspallata, Mendoza): actualización del análisis del contexto funerario. Comechingonia. Revista de Arqueología 20 (1): 21-49.

Da Peña, G., S. Zárate Bernardi, E. Marsh y V. Durán (2018). Una reevaluación del sitio Uspallata Usina Sur. Libro de resúmenes VII JAC: 19. Malargüe.

Durán, V. y C. García (1989). Ocupaciones agro-alfareras en el sitio Agua de la Cueva-sector norte (NO de Mendoza). Revista de Estudios Regionales (CEIDER) 3: 29-64.

Durán, V., G. Lucero, D. Estrella, E. Marsh, L. Yebra y F. Sergo (2012a). Prospección arqueológica del entorno del Cerro El Tunduqueral. Un aporte a la gestión e investigación del patrimonio del Valle de Uspallata. Fondo Provincial de la Cultura. Ministerio de Cultura. Gobierno de Mendoza. Municipalidad de Las Heras.

Durán, V., E. Marsh, G. Lucero, D. Estrella y A. Gasco (2012b). Variante Uspallata Ruta Nacional 7. Evaluación preliminar de impacto arqueológico. Facultad de Filosofía y Letras, Universidad Nacional de Cuyo. Ms

Durán, V., R. Mikkan, G. Lucero, D. Estrella, E. Marsh, R. Pisi y M. N. Quiroga (2010). Parque Municipal Arqueológico Cerro Tunduqueral. Plan de Manejo de Partida. Facultad de Filosofía y Letras, Universidad Nacional de Cuyo. Ms.

Durán, V., G. Neme, V. Cortegoso y A. Gil (2006). Arqueología del Área Natural Protegida Laguna del Diamante (Mendoza, Argentina). Anales de Arqueología y Etnología 61: 81-134.

Durán, V., P. Novellino, L. Menéndez, A. Gasco, E. Marsh, R. Barberena y C. Frigolé (2018). Barrio Ramos I. Prácticas funerarias en el inicio del período de dominación inca del valle de Uspallata (Mendoza, Argentina). Relaciones XLIII (1): 55-86.

Falabella, F., L. Sanhueza, G. Neme y H. Lagiglia (2001). Análisis comparativo de cerámica Aconcagua entre Chile y Argentina. Relaciones XXVI: 193-214.

Frigolé, C. (2017). Tecnología cerámica y movilidad en contextos de cambio. Alfarería del primer milenio A.D. en la zona cordillerana de Mendoza. Tesis Doctoral inédita. Facultad de Filosofía y Humanidades. Universidad Nacional de Córdoba.

Frigolé, C. y A. Gasco (2016). Potters and herders at the southern edge of the Andean world: Risk management and mobility in Northwestern Mendoza, Argentina, Quaternary International, http://dx.doi.org/10.1016/j. quaint.2016.02.032

Frigolé, C., R. Moyano y D. Winocur (2014). Comparando la composición química y petrográfica de distintos estilos cerámicos en una casa del valle de Potrerillos (Mendoza, Argentina). En V. Cortegoso, V. Durán y A. Gasco (eds.), Arqueología de Ambientes de Altura de Mendoza y San Juan (Argentina): 82-99. Mendoza, EDIUNC.

Gambier, M. (1977). La Cultura de Ansilta. San Juan, Instituto de Investigaciones Arqueológicas y Museo. Universidad Nacional de San Juan.

Gambier, M. (2000). Prehistoria de San Juan. San Juan, Editorial Ansilta.

García, A. (1988). Arqueología de La Cueva del Toro (Mendoza - Argentina). Estudios Regionales 1: 17-71.

García, A. (2003). La ocupación temprana de los Andes Centrales Argentinos (ca. 11.000 - 8.000 años C14 AP). Relaciones 28: 153-165. 
García, A. (2009a). El dominio incaico en la periferia meridional del Tawantinsuyu. Revisión de las investigaciones arqueológicas en la región de Cuyo, Argentina. Sociedades de paisajes áridos y semiáridos. Revista Científica del Laboratorio de Arqueología y Etnohistoria de la Facultad de Ciencias Humanas. Universidad Nacional de Río Cuarto. Año I, Volumen I.

García, A. (2009b). El hiatus ocupacional del Holoceno Medio y el registro arqueológico del centro-norte de Mendoza. Arqueología Argentina en los inicios de un nuevo siglo XVIII: 541-549. Rosario, Laborde Editor.

García, A. (2011). El Camino del Inca entre Tocota y Villa Nueva (Valle de Iglesia, San Juan). Revista del Museo de Antropología 4: 89-98.

García, A. (2014). Los petroglifos del Cerro Blanco de Zonda (San Juan). Comechingonia 18 (2): 161-180.

García, A. (2016). Identificación preliminar del arte rupestre Aguada en San Juan. En F. Oliva, A. Rocchietti y F. Solomita Banfi (eds.) Imágenes Rupestres: lugares y regiones: 267-278. Rosario, Facultad de Humanidades y Artes. Universidad Nacional de Rosario.

García, A. y O. Damiani (2020). Sistemas de riego y agricultura prehispánica en el centro oeste de Argentina. Rivar 20: 22-45.

García, A. y P. Sacchero (1989). Investigaciones arqueológicas en Agua de la Cueva-Sector Sur (1987-1988). Revista de Estudios Regionales 4: 27-51.

García Llorca, J. (1991). Estudio arqueológico funcional de una estructura pircada del Tambo de Tambillos (NO de Mendoza). Relaciones con el proceso cultural andino. Seminario de Licenciatura inédito. Facultad de Filosofía y Letras, Universidad Nacional de Cuyo.

1996. Estudio arqueológico del Recinto 4 Unidad D- Sector II del Tambo de Tambillos, Uspallata (Mendoza, Argentina). Relaciones XX: 163-188.

Garvey, R. (2008). A behavioural ecological approach to a proposed middle Holocene occupational gap. Before Farming 2:artículo 2. DOI:10.3828/bfarm.2008.2.2.

Gayo, E., V. McRostie, R. Campbell, C. Flores, A. Maldonado, M. Uribe-Rodriguez, P. Moreno, C. Santoro, D. Christie, A. Muñoz y L. Gallardo (2019). Geohistorical records of the Anthropocene in Chile. Elementa: Science of the Anthropocene 7(1):15. DOI:10.1525/elementa.353.

Gil, A. (1998). Cultígenos prehispánicos en el sur de Mendoza. Discusión en torno al límite meridional de la agricultura andina. Relaciones XXII-XXIII: 295-318.

Gil, A.; G. Neme; R. Tykot: P. Novellino; V. Cortegoso y V. Durán (2009). Stable Isotopes and Maize Consumption in Central Western Argentina. International Journal of Osteoarchaeology 215-236.

Gil, A., R. Villalba, A. Ugan, V. Cortegoso, G. Neme, C. Michieli, P. Novellino y V. Durán (2014). Isotopic evidence on human bone for declining maize consumption during the Little Ice Age in central western Argentina. Journal of Archaeological Science 49: 213-227.

Gil, A., M. Zárate y G. Neme (2005). Mid-Holocene paleoenvironments and the archeological record of southern Mendoza, Argentina. Quaternary International 132:81-94. DOI:10.1016/j.quaint.2004.07.014.

González Carvajal, P. (2013). Arte y cultura diaguita chilena: simetría, simbolismo e identidad. Ucayali Editores, Santiago.

Hart, L. (2009a). Los petroglifos de Santa Elena. Diario Los Andes, 10 de diciembre. Disponible en: www. losandes.com.ar/article/cultura-461397 


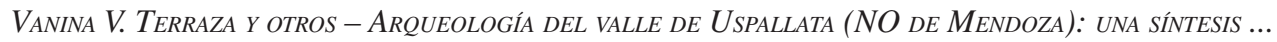

Hart, L. (2009b). Secuencias gráficas. Un recurso común entre el arte prehistórico y el contemporáneo. Ponencia presentada en el Primer Simposio Internacional de Arte Rupestre, Universidad Nacional de Colombia. Disponible en: www.rupestreweb.info/arteprehistorico.html

Hart, L. (2016). Arte de la prehistoria. Diseños rupestres de Cuyo. Mendoza, Zeta Editores.

Hernández Llosas, M. (2006). Inkas y españoles a la conquista simbólica del territorio de Humahuaca: sitios, motivos rupestres y apropiación cultural del paisaje. Boletín del Museo Chileno de Arte Precolombino 11(2): 9-34.

Hogg, A. G., T. J. Heaton, Q. Hua, J. G. Palmer, C. S. M. Turney, J. Southon, A. Bayliss, P. G. Blackwell, G. Boswijk, C. Bronk Ramsey, C. Pearson, F. Petchey, P. Reimer, R. Reimer y L. Wacker (2020). SHCal20 Southern Hemisphere calibration, 0-55,000 years cal BP. Radiocarbon 62: 759-778.

Hyslop, J. (1984). The Inka Road system. Orlando, Academic Press.

Lagiglia, H. (1968). Secuencias culturales del Centro-Oeste Argentino: Valles del Atuel y Diamante. Revista Científica de Investigaciones I (4): 159-174.

Lagiglia, H. (1997). Arqueología de Cazadores Cordilleranos de Altura. San Rafael, ICN Ediciones Ciencia y Arte.

Lagiglia, H. (2002). Los orígenes de la agricultura en la Argentina. En E. Berberian y A. Nielsen (eds.), Historia Argentina Prehispánica vol 1: 41-82. Buenos Aires, Brujas.

Lagiglia, H. (2005). Cerámica de la cultura de La Aguada del Noroeste argentino en Uco Norte de Mendoza. Anales de Arqueología y Etnología 59-60: 29-68.

Lefebvre, H. (1974). La production de l'espace, Anthropos, París.

Lucero, G., V. Cortegoso y S. Castro (2006). Cazadores-recolectores del Holoceno temprano: explotación de recursos líticos en el sitio Agua de la Cueva sector norte. Anales de Arqueología y Etnología 61:185-215.

Marsh, E., S. Castro, V. Cortegoso, K. Carline, S. Buehlman-Barbeau, J. De Alba (2021). Cambios neolíticos fragmentarios en los Andes sur: tendencias cronológicas en los fechados, el paleoclima y el material lítico del valle de Uspallata de Mendoza, Argentina. En evaluación en Chungara Revista de Antropología Chilena.

Marsh, E., R. Kidd y V. Durán (2017). Datación de la expansión del imperio inca: modelos bayesianos de Ecuador y Argentina. Radiocarbon 59 (1): 117-140.

Martel, Á. y S. Giraudo (2014). Semiótica de la imagen en Arqueología: el caso de los 'escutiformes'. Revista Chilena de Antropología Visual 24, 21-45.

Menéndez, L., P. Novellino, L. D’Addona, M. Béguelin, N. Brachetta y V. Bernal (2014). El registro bioarqueológico y la incorporación de las prácticas agrícolas en el Centro- Norte de Mendoza. En V. Cortegoso, V. Durán y A. Gasco (eds.), Arqueología de Ambientes de Altura de Mendoza y San Juan (Argentina) 101125. Mendoza, EDIUNC.

Michieli, C. T. (2011). Estudios recientes sobre la conquista incaica en la alta cordillera de San Juan. En C. Mayol Laferrére, F. Ribero y J. Díaz (eds.), VIII Jornadas de Investigadores en Arqueología y Etnohistoria del Centro-Oeste del País: 41-52. Universidad Nacional de Río Cuarto.

Molleson, T. (2007). A method for the study of activity related skeletal morphologies. Bioarchaeology of the Near East 1: 5-33. 
Montt, I. y G. Pimentel (2003). Grabados antropomorfos tardíos. El caso de las personificaciones de hachas en San Pedro de Atacama (Norte de Chile) En: M. Sepúlveda, J. Chacama y L. Briones (eds.), Crónicas sobre la piedra. Arte Rupestre de las Américas: 221-233. Arica, Universidad de Tarapacá.

Nami, H., V. Durán, V. Cortegoso y M. Giesso (2015). Análisis morfológico-experimental y por fluorescencia de Rayos X de las puntas de proyectil de obsidiana de un ajuar del Periodo Agropecuario Tardío del NO de Mendoza, Argentina. Boletín de la Sociedad Chilena de Arqueología 45: 7-37.

Neme, G. y A. Gil (2009). Human Occupation and Increasing Mid-Holocene Aridity: Southern Andean Perspectives. Current Anthropology 50: 149-163. DOI:10.1086/596199.

Novellino P., L. Menéndez y V. Bernal (2014). Avances en el conocimiento bioarqueológico de las poblaciones humanas del Centro-Norte de Mendoza. En V. Cortegoso, V. Durán y A. Gasco (eds.)Arqueología de ambientes de altura de Mendoza y San Juan (Argentina): 41-53. Mendoza. EDIUNC.

Ots, M. J. (2002). Prospección arqueológica de la cuenca del río de Las Tunas (departamentos de TupungatoTunuyán, Mendoza). Resúmenes VII Jornadas Regionales de Investigación en Humanidades y Ciencias Sociales 393-394. San Salvador de Jujuy, Universidad Nacional de Jujuy.

Ots, M. J. (2004). La presencia inka en el extremo sur-oriental del Kollasuyo: Investigaciones en la cuenca del río De las Tunas (Valle de Uco, Mendoza, Argentina) Resúmenes del XV Congreso Nacional de Arqueología Argentina. 94. Río Cuarto.

Ots, M. J. y P. Cahiza (2013). Caracterización de la frontera suroriental del Tawantinsuyu (Sur de San Juan, norte y centro de Mendoza). Siglos XV y XVI. En M. Gascón y M. J. Ots (eds.), Fronteras y periferias en arqueología e historia: 30-62. Buenos Aires, Editorial Dunken.

Ots, M. J., N. Olizsewski y J. García Llorca (2011). Estrategias alimentarias y de subsistencia prehispánica en el centro oeste de Mendoza. Consumo y descarte en el sitio arqueológico Agua Amarga. Revista del Museo de Antropología 4: 65-80.

Parisii, M. (1994). Algunos datos de las poblaciones prehispánicas del norte y centro oeste de Mendoza y su relación con la dominación inca del área. Xama 4-5: 51-69.

Planella, M. y F. Falabella (1987). Nuevas perspectivas en torno al Período Alfarero Temprano en Chile central. Clava 3: 43-110.

Prieto Olavarría, C., H. Chiavazza, L. Castillo, V. Tobar, E. Bontorno y V. Porta (2017). Estado actual de las investigaciones de la cerámica indígena del norte de Mendoza. Tecnología, cronología y distribución. Revista Del Museo De Antropología 10: 95-104.

Puerto Mundt, S. y E. Marsh (2021). La expansión Tawantinsuyu en Chile central: bases para la construcción de una cronología arqueométrica e integración etnohistórica. Boletín de la Sociedad Chilena de Arqueología. En prensa.

Roig, F. y J. R. Bárcena (1997). Identificación anatómica de maderas actuales y carbones arqueológicos del tambo incaico de Tambillos (Uspallata), Mendoza, Argentina. Parodiana 10 (1-2): 91-112.

Roig, F. y J. R. Bárcena (1998). Interacción metodológica de los estudios anatómicos de maderas actuales, dendrocronológico y antracológico, con los arqueológicos de contextos culturales del norte de Mendoza. Actas y Memorias del XI Congreso Nacional de Arqueología Argentina (17 $7^{\circ}$ Parte). Revista del Museo de Historia Natural de San Rafael XXIX (1/4): 39-59.

Rowe, J. H. (1946). Inca culture at the time of the spanish conquest. En J. H. Steward (ed.) Handbook of South American Indians. Bureau of American Ethnology 2: 183-330, Boletín 143. Washington. 
Vanina V. TerRaza y otros - Arqueología del valle de Uspallata (NO de Mendoza): una síntesis ...

Rusconi, C. (1938-39). Algunos petroglifos de Mendoza. Revista Geográfica Americana. VI-73: 288-290.

Rusconi, C. (1940). Alfarería del tipo peruano en Mendoza. Anales de la Sociedad Científica Argentina CXXIX, II: 88-96.

Rusconi, C. (1956). La ciudadela prehispánica de Ranchillos (Mendoza). Revista del Museo de Historia Natural de Mendoza IX, 1-2: 55-87.

Rusconi, C. (1962). Poblaciones pre y poshispánicas de Mendoza. III: Arqueología. Mendoza.

Rusconi, C. (1965). Ritos Funerarios de los indígenas prehistóricos de Mendoza. Anales de la Sociedad Científica Argentina.

Sabatini, G. y V. Terraza (2013). Distribución del diseño de las cabezas mascariformes en las representaciones rupestres del Centro Oeste Argentino y del Norte Chico Chileno. Estilo, identidad y Paisaje. Espacio, tiempo y forma. Serie I Prehistoria y Arqueología 6: 123-146. Madrid, UNED.

Sanhueza, L., L. Baudet, D. Jackson y L. Contreras (2004). La cultura Agrelo-Calingasta en el Choapa. Werkén 5: 47-52.

Schobinger, J. (1966). La momia del cerro El Toro. Investigaciones arqueológicas en la cordillera de la provincia de San Juan (República Argentina). Anales de Arqueología y Etnología XXI.

Schobinger, J. (1967). Breve Historia de la Arqueología de Alta Montaña en los Andes Meridionales. Boletín de la Sociedad Arqueológica de Santiago de Chile 4: 23-24.

Schobinger, J. (1968). Ruinas incaicas en el Cerro Mercedario, 6770 mts.: Informe sobre la expedición de Alta Montaña de 1968. Actas del XXXVIII Congreso Internacional de Americanistas 1: 429-434. Stuttgart.

Schobinger, J. (1971). Arqueología del Valle de Uspallata. Provincia de Mendoza (sinopsis preliminar). Relaciones 5 (2): 71-84.

Schobinger, J. (1974-76). El enterratorio de Uspallata-Usina Sur (Prov. de Mendoza): estudio de su ajuar funerario. Anales de Arqueología y Etnología XXIX-XXXI: 67-89.

Schobinger, J. (1982). Estudios de Arqueología Sudamericana: Arte Rupestre y Santuarios Incaicos en el Oeste de Argentina. San Antonio de Padua, Buenos Aires, Ediciones Castañeda.

Schobinger, J. (1985). Descripción de las estatuillas que conforman el ajuar acompañante del fardo funerario hallado en el Cerro Aconcagua, provincia de Mendoza. Separata de las Relaciones de la Sociedad Argentina de Antropología 16: 175-190.

Schobinger, J. (1986). La red de santuarios de alta montaña en el Contisuyu y el Collasuyu: evaluación general, problemas interpretativos. Comechingonia, Número Especial: 297-317.

Schobinger, J. (1995a). Informe sobre la relocalización de un hallazgo de Alta Montaña del Noroeste Argentino: la llamada Momia de los Quilmes. Comechingonia 8: 47-67.

Schobinger, J. (1995b). Aconcagua: Un Enterratorio Incaico a 5.300 Metros de Altura. Mendoza, Editorial Inca.

Schobinger, J. (2001). El santuario incaico del cerro Aconcagua. Mendoza, EDIUNC.

Schobinger, J. (2009a) [1982]. Arqueología de la región Cuyana. Esbozo de su prehistoria y protohistoria. En: 
J. Schobinger (ed.), Arqueología y arte rupestre de la región Cuyana 7-50. Mendoza: Facultad de Filosofía y Letras, Universidad Nacional de Cuyo.

Schobinger, J. (2009b). El arte rupestre del occidente argentino. Aspectos generales y ensayos interpretativos. En: J. Schobinger (ed.), Arqueología y arte rupestre de la región Cuyana: 51-70. Mendoza, Editorial de la Facultad de Filosofía y Letras, Universidad Nacional de Cuyo.

Schobinger, J. (2009c). [1982]. Los petroglifos del Cerro Tunduqueral (Uspallata, provincia de Mendoza). En: J. Schobinger (ed.), Arqueología y arte rupestre de la región Cuyana: 93-106. Mendoza, Editorial de la Facultad de Filosofía y Letras, Universidad Nacional de Cuyo.

Schobinger, J. y J. R. Bárcena (1971). El tambo incaico de Tambillitos (Prov. de Mendoza, Argentina). Informe preliminar. Actas del VI Congreso de Arqueología Chilena 397-403. Santiago de Chile.

Sosa, V., A, Nielsen, M. Copa, C. Herrera Salinas y C. Vitry (2020). Camino ancestral Qhapaq Ñan. Una vía de integración de los Andes en Argentina. Ministerio de Cultura de la Nación. Secretaría de Patrimonio Cultural.

Terraza, V. (2013). Desarrollos locales y dominación inkaica en el Valle de Uspallata (NO de la Prov. de Mendoza): Aportes a los estudios ceramológicos del sitio Potrero La Chanchería I. Tesis de Licenciatura inédita. Facultad de Filosofía y Letras, Universidad Nacional de Cuyo.

Terraza, V. (2020). Paisaje y materialidad cerámica en el valle de Uspallata en tiempos del tardío local y de la dominación incaica (1000-1500 DC). Tesis de Doctorado inédita. Facultad de Filosofía y Letras, Universidad Nacional de Cuyo.

Terraza, V. y J. R. Bárcena (2017). Los estilos tecnológicos cerámicos de La Chanchería como indicadores de modos de hacer y de producir de las sociedades tardías del valle de Uspallata (NO de Mendoza). Revista del Museo de Antropología 10: 129-136.

Terraza, V., J. R. Bárcena y J. P. Aguilar (2019). Primeros resultados de las investigaciones arqueológicas en el sitio inca El Chacay (Uspallata, N. O. de Mendoza). Anales de Arqueología y Etnología 74 (1): 73-98.

Terraza, V. y A. Auteri (2020). Materialidad, agencia y linealidad cerámicas durante la dominación inca en el valle de Uspallata (Mendoza, Argentina). Dominios Da Imagem 14 (27): 230-253. DOI: http://dx.doi. org/10.5433/2237-9126.2020v14n27p229

Troncoso, A. (2008). Arte rupestre en la cuenca del Río Aconcagua: Formas, sintaxis, estilo y poder. Traballos de Arqueoloxia e Patrimonio (TAPA). Santiago de Compostela. Instituto de Estudos Galegos Padre Sarmiento.

Zárate Bernardi, M. S. (2017). Definición estilística de los petroglifos del cerro Tunduqueral: debates y perspectivas cronoculturales. Tesis de Licenciatura inédita. Facultad de Filosofía y Letras. Universidad Nacional de Cuyo.

Zárate Bernardi, M., Piazze, L., Cuervo, J., Gasco, A. y V. Durán (2019). Ante la emergencia lo posible. Recursos interpretativos en el Cerro Tunduqueral. Revista de Sociedades de Paisajes Áridos y Semiáridos XII (1): 230-252.

Zárate Bernardi, S., Puerto Mundt, S. y E. Marsh (2020). Arte rupestre al sur del Tawantinsuyu: síntesis comparativa de las vertientes oriental y occidental de Los Andes. Cuadernos de Arte Prehistórico, Número Especial 1: 52-88. 